\title{
Alejandro Magno en el cómic norteamericano y europeo del siglo XX: un análisis desde la didáctica de la historia
}

Alexander the Great in 20th century American and European comic: an analysis from Teaching History

Julián Pelegrín Campo*

\section{Resumen}

Tras constatar la existencia de un corpus de más de doscientos cómics publicados a lo largo de casi un siglo que incorporan representaciones gráficas de Alejandro Magno, en el presente trabajo se analizan aquellas obras que muestran al personaje desde una perspectiva históricobiográfica y con una finalidad didáctica publicadas por vez primera en los Estados Unidos de la década de 1920 bajo la forma de tiras de prensa y dos décadas más tarde en Europa en tanto que contenidos de las revistas destinadas a un público infantil, así como su posterior evolución en ambos escenarios geográficos a lo largo del siglo XX.

Palabras clave: Alejandro Magno. Cómic norteamericano. Cómic europeo. Recepción clásica. Didáctica de la Historia.

\begin{abstract}
After verifying the existence of a corpus of more than two hundred comics published over almost a century that incorporate graphic representations of Alexander the Great, in this article are analyzed those works that show the character from a historical-biographical perspective and with a didactic purpose, first the works published in the United States in the 1920s in the form of newspaper strips, and twenty years later the works published in Europe as magazine contents aimed at a child audience, as well as their subsequent evolution in both geographical settings to throughout the 20th century.
\end{abstract}

Key words: Alexander the Great. American comic. European comic. Classical reception. History instruction.

\section{Introducción}

Tras abordar en otros trabajos las posibilidades didácticas que a propósito de la historia de Alejandro Magno ofrece en el ámbito hispano la combinación de texto e imagen en formatos como el libro informativo y el libro-álbum (Pelegrín Campo, 2008 y 2011), en el número anterior de esta misma revista publicamos una primera

\footnotetext{
*Universidad de Zaragoza•ORCID 0000-0003-4425-0864• jpelegri@unizar.es
}

Pelegrín Campo, J. (2020). Alejandro Magno en el cómic norteamericano y europeo del siglo XX: un análisis desde la didáctica de la historia. CLIO. History and History teaching, 46, 283-326. https://doi.org/10.26754/ojs clio/clio.2020465331. Recibido: 13/06/2020. Aceptado: 15/10/2020. 
aproximación a la presencia de Alejandro Magno en el cómic en la que denunciábamos hasta qué punto este tema ha sido prácticamente ignorado por los estudios sobre la recepción de la Antigüedad clásica en general y la de este personaje en particular -lastradas en su inmensa mayoría por perspectivas academicistas escasamente interesadas por las manifestaciones de la cultura popular contemporánea más allá del cine y de la novela histórica- y muy escasamente examinado por los que abordan el tratamiento del mundo antiguo en dicho género, cuando, en realidad, la existencia de más de doscientos títulos publicados a lo largo de casi un siglo que incorporan representaciones gráficas de Alejandro constituye un corpus con entidad más que suficiente como para ser reconocido en tanto que objeto de estudio por la investigación académica a la vista tanto de la importancia del personaje como icono de referencia en el marco de la cultura popular contemporánea como de sus posibilidades educativas en el ámbito de la didáctica de la Historia (Pelegrín Campo, 2019).

En ese mismo trabajo proponíamos una serie de posibles vías de investigación que consideramos de interés a la hora de abordar esta particular recepción de Alejandro Magno, entre las cuales apuntábamos la aparición de las primeras obras dedicadas al personaje, siempre desde una perspectiva histórico-biográfica y con una finalidad didáctica, primero en los Estados Unidos de la década de 1920 bajo la forma de tiras de prensa y dos décadas más tarde en Europa en tanto que contenidos de revistas destinadas a un público infantil, así como su posterior evolución en ambos escenarios geográficos a lo largo del siglo $\mathrm{XX}$ hasta desembocar en el panorama actual que repasábamos en la última parte de nuestro análisis. $Y$ son precisamente esos dos escenarios los que constituyen el objeto de nuestro interés en el presente estudio, que se iniciará con el cómic estadounidense por tratarse del contexto en el que irrumpe Alejandro Magno en este género -tanto en el cómic de carácter histórico-biográfico como en el ficcional- y continuará con las producciones europeas, comenzando en este caso con el cómic español -el primero en Europa en el que aparece la figura de Alejandro- para pasar a continuación a la bande dessinée franco-belga y a algunas publicaciones editadas en otros países en las que se advierte un tratamiento especialmente significativo del personaje a la vista del contexto en el que aparece evocado. 


\section{Alejandro Magno en el cómic didáctico norteamericano del siglo XX}

Los Estados Unidos proporcionan el escenario sobre el que encontramos no sólo el origen y más temprano desarrollo de la utilización del cómic como recurso didáctico, sino también la más antigua presencia de Alejandro Magno en un título de este género, concretamente en las tiras publicadas en la prensa diaria. Ya en 1918 Winsor McCay, uno de los padres del cómic y de la animación, había publicado en el Boston Advertiser \& American una ilustración en la que mostraba al espectro de Alejandro junto a los de Julio César, Teodorico, Federico II el Grande de Prusia y Napoleón como los conquistadores a los que desde niño ansiaba superar un káiser Guillermo II que, atraído por ellos, avanza hacia un abismo lleno de cadáveres identificado como el resultado de su participación en la Gran Guerra cuando ésta todavía asolaba Europa ${ }^{1}$. Pero más allá de la ilustración política, entre los cómics propiamente dichos sobre Alejandro Magno el más antiguo de los que tenemos noticia es el que inaugura la colección Men Who Made The World, una serie de biografías de personajes históricos famosos -Julio César, Juana de Arco, Hernán Cortés, George Washington y Napoleón, entre otros- publicadas bajo la forma de tiras de prensa en diarios norteamericanos entre 1925 y 1927 y distribuidas por la John F. Dille Company (el posterior National Newspaper Syndicate). Las 33 tiras que conforman este Alexander the Great aparecieron de lunes a sábado entre el 21 de septiembre y el 28 de octubre de 1925 en periódicos de Estados Unidos -así The Orlando Evening Star (Orlando, Florida)- y de Canadá - The Border Cities Star (Windsor, Ontario)-, con un dibujo en blanco y negro de Chester Sullivan, ausencia absoluta de diálogos y profusión de textos explicativos al pie redactados al principio por Granville E. Dickey (tiras 1-6) y más tarde por Elliot Shoring (tiras 7-33), el segundo de los cuales es presentado en los créditos con el título de "Doctor" y como "the Noted Historian". El dibujo se simplifica progresivamente conforme se ve arrinconado por textos cada vez más extensos que repasan por orden cronológico la trayectoria del protagonista, desde los prodigios asociados a su nacimiento hasta la llegada de sus restos a Alejandría. Y a pesar de lo reducido del formato y de incurrir en errores como la presentación de las ciudades del Imperio persa coronadas con cúpulas bulbosas de acuerdo con la visión estereotipada

\footnotetext{
1 Resulta obligado corregir y completar las informaciones apuntadas en un trabajo anterior (Pelegrín Campo, 2019, p. 377, n. 43) señalando que dicha ilustración acompaña al editorial titulado "Five Men Have Inspired the Kaiser" publicado en el Boston Advertiser \& American el domingo 17 de marzo de 1918 y que puede ser consultada en McCay (2005, p. 127) y en las colecciones digitales de The Ohio State University (https://hdl.handle.net/1811/d4e5b641-182d-4801-81fe-03c3ac8079b2).
} 
de Occidente que asocia todo lo oriental con Las mil y una noches (así Babilonia en la tira $n .021$, Persépolis y Susa en la 22 y de nuevo Susa en la 29), aporta abundante información e incluye asimismo elementos didácticos como mapas (de la ruta de

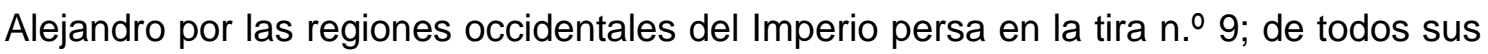
dominios en la 14; de Egipto en la 15; de las regiones orientales en la 30; del Mediterráneo en 323 en la 32) y esquemas del desarrollo de las batallas (Gránico en la tira n. 8; Issos en la 10; Arbelas en la 20; Hidaspes en la 30$)^{2}$.

Sin embargo, ésta no era sino una versión a menor escala de la fórmula inaugurada un año antes por James Carroll Mansfield con High Lights of History, la tira norteamericana de carácter educativo más antigua -apareció el 17 de noviembre de 1924- y la de no-ficción editada durante más tiempo -hasta 1942-. Distribuida por Bell Syndicate y publicada en la prensa estadounidense al principio de lunes a sábado bajo la forma de una sola tira en blanco y negro y posteriormente también en la edición dominical ocupando una página completa en color, esta sección se centraba en un acontecimiento o en un personaje histórico y en dos ocasiones dedicó su espacio a la biografía de Alejandro Magno. La primera versión apareció en sendas páginas completas publicadas los días 15 y 22 de enero de 1928 en la "Color Section" de The Sunday Star (la edición dominical de The Evening Star, Washington D.C.) y posteriormente en otros diarios -así el 29 de abril y el 6 de mayo de ese mismo año en The Los Angeles Times (Los Ángeles, California)-: carentes de diálogos y acompañadas con textos descriptivos al pie, la titulada "The Early Career of Alexander the Great" cuenta con 16 viñetas repartidas en cuatro filas que alcanzan desde el nacimiento del personaje hasta el episodio del nudo gordiano, mientras que "The Conquests of Alexander the Great" muestra en el encabezado un mapa del recorrido de Alejandro por Asia al que siguen 18 viñetas distribuidas en tres filas que abarcan

\footnotetext{
${ }^{2}$ Ediciones de esta obra publicadas en diarios como los ya mencionados y los estadounidenses The Brooklyn Daily Eagle (Brooklyn, Nueva York, octubre-noviembre de 1925), The Morning Herald y The Daily Mail (Hagerstown, Maryland, abril-mayo de 1926) y Reading Times (Reading, Pennsylvania, abrilmayo de 1926) pueden ser consultadas en las hemerotecas digitales de la Library of Congress (http://eresources.loc.gov/) y de la Brooklyn Public Library (https://bklyn.newspapers.com/papers/), en Google News (https://news.google.com/newspapers?nid=IlaPce-xyHYC), así como en los repositorios https://newspaperarchive.com y https://www.newspapers.com. Entre 1927 y 1929 fue publicada semanalmente en La Presse de Québec la versión coloreada y en francés de la serie bajo el título Les grandes figures de l'histoire du monde, dentro de la cual apareció en 1929 Alexandre le Grand, cuyas dos primeras tiras se muestran en https://www.lambiek.net/artists/s/sullivan chester.htm; sobre la serie y la revista, vid. quebec.wikia.com/wiki/Les Grandes Figures de 1\%27Histoire du Monde - La Presse.
} 
desde su desembarco en Asia hasta su fallecimiento en Babilonia ${ }^{3}$. La segunda versión fue publicada igualmente en la edición dominical de varios periódicos estadounidenses a lo largo de ocho entregas consecutivas comprendidas entre el 17 de febrero y el 7 de abril de 1935 y tituladas respectivamente "The Boyhood of Alexander the Great" (que incluye episodios como la doma de Bucéfalo o las enseñanzas de Aristóteles), "The Young Alexander" (con Queronea y el exilio de Macedonia), "Alexander as King" (desde la muerte de Filipo a la destrucción de Tebas), "Alexander Sets Out" (desde el cruce del Helesponto a la batalla de Issos), "Alexander the Great" (de Issos a Egipto), "Alexander the Great" (de Egipto a la muerte de Darío), "Alexander the Great in Asia" (de Arbelas a la India) y "The End of Alexander" (de la India a la muerte de Alejandro en Babilonia). Sin embargo, en este caso su extensión se limita a algo menos de media página -compartida con otras secciones de carácter didáctico elaboradas por el mismo autor como Boys and Girls the World Over y Jolly Geography - integrada por dos o, más frecuentemente, tres tiras de tres o cuatro viñetas cada una acompañadas por textos explicativos -dispuestos al principio en columnas y posteriormente al pie de la imagen- y por escasísimos bocadillos de diálogo ${ }^{4}$.

Tanto en la serie Men Who Made The World como en las dos versiones publicadas de High Lights of History la aproximación a la figura de Alejandro resulta puramente biográfica y se plasma gráficamente en una representación no caricaturizada, sino realista del personaje. Pero, en la medida en que se centra exclusivamente en aspectos positivos y a menudo anecdóticos de su vida y obra, este tipo de cómic incorpora un tono ejemplarizante que, unido al contexto de aventura en el que se enmarca, delata una naturaleza didáctica propia de un producto destinado al público

\footnotetext{
${ }^{3}$ Las dos páginas editadas en The Sunday Star pueden ser consultadas en la hemeroteca digital de la Library of Congress (https://chroniclingamerica.loc.gov/lccn/sn83045462/1928-01-15/ed-1/seq-114/ y https://chroniclingamerica.loc.gov/lccn/sn83045462/1928-01-22/ed-1/seq-100/). Su publicación se enmarca en una serie dominical de High Lights of History iniciada el 14 de noviembre de 1926 que repasa por orden cronológico la Historia Universal y que incluye inmediatamente antes títulos protagonizados por Filipo de Macedonia (ก.. 60, 1 de enero de 1928) y Demóstenes (n.. 61, 8 de enero) y a continuación otros dedicados a Cartago y la Primera Guerra Púnica (n. ${ }^{64}, 29$ de enero) y a Aníbal (n. 65, 5 de febrero).

${ }^{4}$ La edición en blanco y negro publicada por The Evening Star puede ser consultada completa en la hemeroteca digital de la Library of Congress (a partir de https://chroniclingamerica.loc.gov/lccn/sn83045462/1935-02-17/ed-1/seq-83/), mientras que de la edición en color el site web Comic Book Plus exhibe las entregas n. $.03,6$ y 7 pubicadas en las mismas fechas por The Newark Ledger (Newark, Delaware: https://comicbookplus.com/?dlid=58436, la primera de ellas bajo el título "Alexander Becomes King") y las n.. 1, 2 y 8 reeditadas dos años más tarde en la revista Famous Funnies (n.. 36, 37 y 39, correspondientes a julio, agosto y octubre de 1937 respectivamente, ed. Eastern Color: https://comicbookplus.com/?dlid=36706).
} 
más joven, tal como se evidencia en la publicidad con la que los diferentes diarios anuncian o recuerdan la aparición de ambas series ${ }^{5}$, en los mensajes que recuerdan la posibilidad de reunir todas entregas en una historia universal coleccionable e incluso en su eventual ubicación en páginas de los periódicos destinadas específicamente a ese tipo de lector 6 . Y precisamente como consecuencia de esta identificación, el producto pronto quedará etiquetado como una obra menor, de extensión reducida y publicación limitada a las revistas infantiles y juveniles, que es el formato en el que lo encontraremos en adelante. De hecho, tal como ya se ha apuntado, tres de las ocho entregas de High Lights of History que integran la segunda versión de la biografía de Alejandro fueron reeditadas durante 1937 en la revista mensual Famous Funnies (ed. Eastern Color) ${ }^{7}$. $Y$ es precisamente esta revista la que al año siguiente incorpora a Alejandro Magno, junto con otros personajes históricos, como interlocutores del personaje cómico Seaweed Sam, el cual, después de haberles traído al presente al abrir "las botellas del tiempo", provoca su ira al atribuirles erróneamente el protagonismo de acontecimientos diferentes a aquellos en los que participaron -así, considera a Alejandro el derrotado en Waterloo, mientras que asigna a Toro Sentado el deseo alejandrino de que existieran más mundos para conquistar-y finalmente es el propio lector quien debe responder correctamente en los apartados destinados a ello en la última viñeta (Famous Funnies, números 46 y 47, mayo y junio de 1938

\footnotetext{
${ }^{5}$ El anuncio insertado en The Evening Star el 13 de noviembre de 1924 comunica a sus lectores la aparición diaria de High Lights of History a partir del 17 del mismo mes presentando esta obra como "The Complete History of Civilization Showing the World's Development in Discoveries, Governement, Science, Invention, Transportation, Communication, Commerce, Industry and Natural Resources" e insistiendo en el componente didáctico de la misma con los mensajes "Told Daily in Pictures in the Great Educational Strip" y "An Education for All Ages" (p. 10: https://chroniclingamerica.loc.gov/lccn/sn83045462/1924-1113/ed-1/seq-10/), mientras que el publicado en The Border Cities Star el martes 29 de septiembre de 1925 presenta la colección Men Who Made The World iniciada una semana antes en ese mismo diario precisamente con la serie dedicada a Alejandro Magno- mediante fórmulas como "a great new feature presenting in superb World-Picture form the dramatic and inspiring life stories of the leading personalities of all time", "a picturesque pageantry of those towering characters whose personality and force have shaped the world" $y$ "all that is dramatic, all that is inspiring, all the events and incidents which these men met as they swept toward the heights", insiste en la calidad del producto resaltando la de sus autores en tanto que "superbly told by the writer-historian, Granville E. Dickey, and pictures by the noted illustrator Chester Sullivan" e igualmente lo recomienda para un público generalista representado por "every reader of this paper-grownups and children" (p. 13: https://news.google.com/newspapers?nid=IlaPcexyHYC\&dat=19250928\&printsec=frontpage\&hl=es).

${ }^{6}$ High Lights of History siempre incluye en el pie de página el mensaje "If You Save This Page Each Week You Will Have a Complete History of Man", y en su edición publicada por The Los Angeles Times (Los Ángeles, California) estas páginas figuran dentro del suplemento "The Junior Times".

${ }^{7}$ Vid. n. 4. Impulsada por Maxwell C. Gaines, Famous Funnies es considerada el primer cómic moderno y el origen de la industria norteamericana del cómic, concebido en adelante ya no como obsequio por la compra de un determinado producto, sino como producto específico, de venta en quiosco, con precio propio, amplia tirada y un formato que se convirtió en estándar (Coletta, 2010).
} 
respectivamente, ed. Eastern Color $)^{8}$. Sin embargo, un año antes el fenómeno ya se constata en la revista More Fun Comics (ed. DC Comics) con la publicación de The Magic Crystal of History. Creada por Adolphe Barreaux, esta serie representa el primer cómic sobre viajes en el tiempo al establecer una conexión de naturaleza fantástica entre pasado y presente gracias a una esfera de cristal que permitía a una pareja de hermanos integrada por un chico, Bobby, y una chica, Binks, ya sea viajar a diferentes momentos de la Historia para acompañar a determinados personajes y presenciar ciertos sucesos o, como en el número dedicado a Alejandro Magno, contemplar acontecimientos de distintas épocas a través precisamente de dicha esfera. En este último caso las dos páginas en color de Homer Fleming publicadas sin título específico en septiembre de 1936 ( $n$. ํ 13, pp. 62-63) se limitan básicamente a destacar el genio militar del macedonio evocando una estratagema utilizada contra los tracios y la descripción de la falange dispuesta frente a los ilirios, dos episodios menores y ajenos a su mayor hazaña, la conquista del Imperio Persa, tal como nos los presentan Bobby y Binks, cuyo limitado diálogo no hace más que completar el abundante texto explicativo que acompaña a las imágenes ${ }^{9}$.

La publicación de The Magic Crystal of History fijó la pauta para la generalización en los años posteriores y hasta nuestros días de historietas puramente lúdicas en las que Alejandro Magno es contemplado ya sea directamente por viajeros temporales que visitan el pasado -protagonistas de series propias como Stuart Taylor in Weird Stories of the Supernatural, de Curt Davies (Jumbo Comics, n..$^{17}$, julio de 1940, ed. Fiction House), o Mark Swift and the Time Retarder, de Jack y Otto Binder (Slam-Bang Comics, n. 6 , agosto de 1940, ed. Fawcett)- o bien a través de ingenios mágicos desde el presente -como Rex Dexter en The Planet That Feared Earth, de Dick Briefer

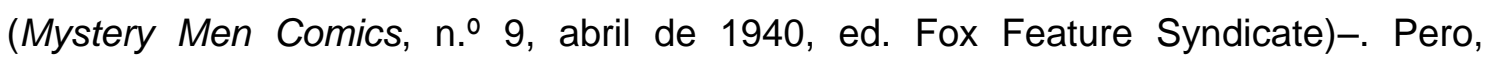
paralelamente, la aproximación biográfica a la figura de Alejandro en términos puramente históricos continuará presente en el cómic norteamericano, asociada por una parte al estallido y desarrollo de la Segunda Guerra Mundial y por otra al nacimiento de un cómic específicamente educativo.

${ }^{8}$ Las dos páginas pueden ser consultadas en https://comicbookplus.com/?dlid=35162 y https://comicbookplus.com/?dlid=62174.

${ }^{9}$ La obra puede ser consultada en http://comicbookplus.com/?dlid=11616. A pesar de ser ésta la única historieta de la serie en la que al final figura el rótulo "Continued", en ninguna de las demás entregas vuelve a aparecer Alejandro. 
Por lo que a la primera se refiere, en septiembre de 1941 y junto a historietas policíacas, de cowboys y superhéroes -estos últimos ya enfrentados en ocasiones al futuro enemigo nazi-, la revista mensual Master Comics inauguró una sección integrada por una sola página titulada Famous Blitzkriegs of the past! y dedicada en su estreno a Alejandro Magno, el cual aparece representado, por una parte, en una viñeta circular a modo de retrato y, por otra, al frente de sus tropas derrotando al enemigo persa, junto a un texto que proclama que la "guerra relámpago ... no fue inventada por Hitler" y que la falange macedónica "fue la original 'punta de lanza' o fuerza 'Panzer' mucho antes de Hitler y sus tanques" (Master Comics, no 18, sept. de 1941, p. 50, ed. Fawcett Publications Inc. $)^{10}$. Como en el episodio de The Magic Crystal of History, el formato biográfico se concreta en un acontecimiento particular referido a la capacidad militar de Alejandro, pero en este caso con la evidente intención de restar mérito a los éxitos obtenidos por Hitler en Europa desde un año antes, en una relectura interesada del personaje determinada por el contexto histórico en el que resulta formulada ${ }^{11}$.

Simultáneamente asistimos a la aparición de un nuevo fenómeno, decisivo para entender la presencia de Alejandro en el cómic de la época. En respuesta a las críticas dirigidas desde algunos sectores contra lo que consideraban la perniciosa influencia sobre niños y jóvenes de un género hasta entonces dominado por la ficción y el entretenimiento y cuya circulación mensual de 10 millones de ejemplares era cinco veces superior a la publicación anual de libros infantiles, en 1941 The Parents' Institute, responsable de la revista Parents' Magazine, impulsó la edición de cómics educativos centrados en personajes -héroes de guerra, exploradores, políticos, atletas, pioneros de la medicina- y acontecimientos históricos -a menudo batallas, pero también descubrimientos geográficos y científicos, así como inventos- con el objetivo, según el editor George J. Hecht, de "sublimar y redirigir un interés infantil

\footnotetext{
${ }^{10}$ La página puede ser consultada en http://comicbookplus.com/?dlid=61805. Fue reeditada en diciembre de ese mismo año en el n. $\stackrel{1}{1}$ de Xmas Comics, un volumen recopilatorio anual publicado igualmente por Fawcett.

${ }^{11}$ La sección Famous Blitzkriegs of the past! continuó publicándose durante unos meses bien en esa misma revista o en otras editadas asimismo por Fawcett -Minute Man, Spy Smasher, Captain Marvel Adventures, Whiz Comics y Bulletman- para evocar los éxitos militares de personajes como Ciro, Jerjes, Escipión el Africano, Alarico, Atila, Carlos Martel, Godofredo de Bouillon y Eduardo III de Inglaterra con la misma finalidad de minimizar los de Hitler -ya sea por resultar aquéllos superiores o, simplemente, cronológicamente anteriores-, si bien el líder nazi vuelve a ser mencionado de manera explícita sólo en las tres entregas que en octubre, noviembre y diciembre de 1941 suceden a la de Alejandro-dedicadas a Aníbal, Julio César y Gengis Kan respectivamente- y desaparece precisamente tras el ataque japonés a Pearl Harbor, un acontecimiento que desplaza el interés por Hitler y por su "guerra relámpago" como consecuencia de la irrupción de un nuevo enemigo enfrentado de manera directa con los Estados Unidos en un escenario bélico diferente y que termina poniendo fin a la sección misma en agosto de 1942.
} 
poderoso y ahora profundamente arraigado" (cit. en Beaty, 2005, p. 109; Duncan, Taylor y Stoddard, 2016). En el artículo "What to Do About the Comics?", publicado en el número 16 de dicha revista en marzo de ese año, Clara Savage Littledale anunciaba como editora de la misma que este nuevo producto

"es del mismo tamaño, de la misma apariencia general que las otras revistas de cómics. Son las mismas 64 páginas de imágenes de colores brillantes (...) La diferencia radica en el tema, que trata de la historia actual y pasada (...) Cada página en esta nueva revista de cómics está llena de acción y emoción. Pero los héroes no son personajes imposibles (...) Son los hombres a quienes los niños deberían conocer y admirar, con cuyos logros deberían estar familiarizados" ( $p$. 27, cit. en Lopes, 2009, p. 33, y Jacobs, 2013, p. 87).

El comentario de Littledale apuntaba a la inmediata publicación al mes siguiente de la revista True Comics: con una periodicidad bimestral y el lema -parafraseando a lord Byron- "TRUTH is Stranger and a Thousand Times more Thrilling than FICTION", fue el primer cómic que incorporó a su consejo asesor pedagogos e historiadores en tanto que especialistas de los temas allí tratados. De hecho, en el mismo artículo Littledale añadía:

"Si bien True Comics está destinada fundamentalmente a la diversión de los niños en su tiempo libre, se cree que muchas escuelas encontrarán esta nueva revista de la mayor ayuda como lectura complementaria para los cursos de historia y ciencias sociales" (ibid., 93, cit. en Jacobs, 2013, p. 87).

Y si True Comics nacía en abril con un objetivo centrado ya no sólo en la sustitución de "malos cómics" por "buenos cómics", sino en la atribución de un valor didáctico añadido a estos últimos (Jacobs, 2013), en septiembre le siguieron revistas similares con títulos asimismo tan inequívocos acerca de sus contenidos como Real Heroes y Real Life Comics ${ }^{12}$. Resulta significativo comprobar cómo ya desde su primer número cada una de estas revistas aúna la doble vía a la que antes nos referíamos al combinar esa aproximación didáctica a la historia real con el protagonismo otorgado a personajes y acontecimientos relacionados con el contexto histórico en el que estas publicaciones nacen: una Segunda Guerra Mundial por aquel entonces todavía limitada al escenario europeo ${ }^{13}$. Esta aproximación se acentuará tras el ataque

\footnotetext{
${ }^{12}$ Real Heroes fue publicada igualmente por The Parents' Magazine Press bajo el lema 'Not about impossible supermen, but about real-life heroes and heroines who have made and are making history!", mientras que Real Life Comics fue editada por Better / Nedor / Standard / Pines Publications con el eslogan "True adventures of the world's greatest heroes!".

${ }^{13}$ True Comics abre su primer número con la biografía de Winston Churchill, presentado como "El héroe mundial número 1" (http://comicbookplus.com/?dlid=24813), y Real Heroes con la biografía de Franklin D.
} 
japonés a Pearl Harbor y la consiguiente entrada de Estados Unidos en el conflicto, y así el número 5 de Real Life Comics, publicado en mayo de 1942, refleja en sus páginas la preocupación por sucesos tan recientes como el abandono de Filipinas por el general MacArthur ante el avance japonés (ocurrido tan sólo dos meses atrás) y la rendición de las tropas filipinas y norteamericanas que permanecían en las islas (acontecida apenas un mes antes). En este caso la revista se abre con una presentación a cargo del editor titulada "Homage to Heroes" en la que MacArthur y sus tropas, como parte de "un nuevo ejército de héroes" que "está surgiendo", son asociados con las hazañas realizadas a lo largo de la historia por los gobernantes de una China ahora aliada en la lucha contra Japón "para defender su nación y la democracia", por destacados militares norteamericanos e incluso por Alejandro Magno, presentado como "brillante general, hombre de Estado, fundador del comercio marítimo y promotor de la unidad entre las naciones" (p. 2, sección "Talks with the editor" $)^{14}$. La portada muestra el rostro dibujado de Alejandro flanqueando, junto a los de cuatro héroes estadounidenses -entre ellos el famoso general Custer, la representación genérica de un marine y un oficial caído días antes en Luzón-, un británico y varias escenas de la guerra en China, una vista general de Chiang Kaishek, el cual, acompañado por una figuración femenina de dicho país, avanza pisando y atravesando con su espada la bandera de Japón. Y en el interior, con un dibujo muy dinámico de Henry C. Kiefer acompañado ya no sólo de textos al pie, sino también de auténticos diálogos bajo la forma de bocadillos, se dedicarán nada menos que diez páginas en color a narrar la historia de un Alejandro ya adulto, pues la narración comienza con el reconocimiento de Filipo como hegemón de la Liga de Corinto, prescindiendo, en consecuencia, no sólo de las consabidas anécdotas infantiles, sino incluso de su actuación en la batalla de Queronea. Alejandro aparece idealizado bajo una imagen, la de héroe civilizador y gobernante modélico, que de manera implícita facilita su asociación ideológica con unos valores -la defensa de la libertad y la lucha contra la tiranía- asumidos como propios tanto por los editores como por el gobierno

Roosevelt, "El hombre más importante de la Tierra" (http://comicbookplus.com/?dlid=22579), mientras que Real Life Comics agrupa en torno a un elogio de la democracia una serie de relatos entre los que se cuenta "I Fight the Nazis" (http://comicbookplus.com/?dlid=65168). Y todavía en 1944 aparecerá It really happened (ed. William H. Wise) bajo el lema "Popular Heroes of the Past and Present" y con historias ambientadas en ese mismo contexto bélico (https://comicbookplus.com/?dlid=46297).

${ }^{14}$ La obra puede ser consultada en http://comicbookplus.com/?dlid=58525. La vinculación de Alejandro con la idea del comercio como instrumento de civilización se remonta a la relectura que autores europeos de los siglos XVIII y XIX como Montesquieu y Droysen hacen de la imagen del personaje proporcionada a su vez por la Anábasis de Arriano y Sobre la fortuna o la virtud de Alejandro de Plutarco (Moreno Leoni, 2017). 
de los Estados Unidos y, en consecuencia, transmitidos a los lectores para elevar la moral patriótica en un contexto bélico desfavorable ${ }^{15}$. E incluso una vez finalizado el conflicto, en el único número de la revista Medal of Honor Comics, de A. S. Curtis, publicado en la primavera de 1946 bajo el subtítulo True Tales of THE NATION'S HIGHEST AWARD FOR VALOR, la narración de las hazañas realizadas durante el mismo por una serie de combatientes galardonados por ello con la Medalla de Honor del Congreso de los Estados Unidos se ve precedida por una historia de esta condecoración que incluye entre sus precedentes las recompensas a los servicios militares concedidas por Alejandro Magno (p. 4$)^{16}$.

Dentro de esa misma producción de un cómic educativo centrado en realidades históricas se sitúa la labor editorial del ya mencionado Maxwell C. Gaines. Antiguo maestro y director de escuela, a las aventuras de Wonder Woman creadas por William Moulton Marston y publicadas a partir de 1942 en la revista homónima asoció desde el primer número la sección "Wonder Woman of History" (ed. DC), cuyas cuatro páginas difundieron a lo largo de 66 entregas las biografías de personajes históricos femeninos como Florence Nightingale y Marie Curie e incluso fueron distribuidas en las escuelas públicas como cuadernillo grapado independiente (Lepore, 2014) ${ }^{17}$. A la vez Gaines editó de manera independiente y como suplemento de un periódico las diez entregas de Picture Stories from the Bible (1942) y en 1944 fundó la editorial Educational Comics (conocida posteriormente como Entertaining Comics y finalmente como EC), con la que publicó las cuatro entregas de Picture Stories from American History (19451947), las dos de Picture Stories from Science (1947) e igualmente las dos de Picture Stories from World History (1947) (Duncan, Taylor y Stoddard, 2016). Esta última serie, dibujada por Harley Griffiths, redactada básicamente por la profesora de Historia en Educación Secundaria Anne Quattrocchi, y comercializada con precios especiales

\footnotetext{
${ }^{15}$ De hecho, la asociación de Alejandro con esos mismos valores de defensa de la libertad y lucha contra la tiranía reaparece en el cómic ficcional cuando en abril de 1944 la serie Commando Ranger, con guión de Jock Lawrence y dibujo de Art Saaf (Ranger Comics, 16, ed. Fiction House), muestra al protagonista homónimo infiltrándose en territorio balcánico más allá de las líneas enemigas para facilitar un eventual desembarco de los Aliados desde el Adriático - planteado en la ficción apenas tres meses antes del que tuvo lugar en Normandía- y colaborando allí con Sandra, líder de la resistencia local contra los invasores nazis en virtud de su condición de heredera de Alejandro Magno, la cual queda demostrada ya no sólo por su onomástica, sino sobre todo al extraer de una piedra el hacha del conquistador al modo de la Excalibur artúrica; la obra puede ser consultada en https://comicbookplus.com/?dlid=24513.

${ }^{16}$ La obra puede ser consultada en https://comicbookplus.com/?dlid=1593.

17 La colección casi completa puede ser consultada en http://wonderwoman.wikia.com/wiki/Wonder Women of History.
} 
para los ejemplares destinados a su utilización en el aula, se presentaba en el prólogo de su primer número como un producto que

\begin{abstract}
"ilustra el amplio panorama del desarrollo de la civilización y del progreso político, económico y social desde los días más antiguos hasta la época actual, y a la vez que está escrito y realizado en el estilo popular de narración a través de la imagen, no sacrifica nada a la exactitud histórica" ("Foreword", n. 1, 1947, p. 2).
\end{abstract}

Precisamente en ese primer número, dedicado a la historia de la humanidad desde sus orígenes hasta la caída del Imperio Romano y completado con una cronología básica ("Important dates to remember", p. 47) y un índice alfabético de personajes y términos históricos (desde "Acrópolis" a "Zoroastro", p. 46), además de la portada adornada con un medallón en el que figura el retrato de Alejandro encontramos al final de la sección "The story of Greece" una página referida al personaje a partir de cinco viñetas dedicadas respectivamente al ascenso de Macedonia, la doma de Bucéfalo y el magisterio de Aristóteles, el ascenso al trono, la conquista de Asia y su legado cultural, plasmado en la Biblioteca de Alejandría (p. 30). Con todo, aun cuando Picture Stories from World History encerraba una finalidad explícitamente educativa e incluso fue la primera publicación de este tipo en incorporar como recurso didáctico un mapa histórico en color del imperio de Alejandro que identifica las diferentes regiones del mismo -si bien no muestra sus límites orientales (p. 31)-, sin embargo la extremada concisión narrativa, la escasez de diálogos y la abundancia de cuadros de texto explicativos no favorecen precisamente la comprensión histórica del personaje ni de su época.

De hecho, la fórmula del cómic educativo, descrita como "género marginal del medio ya culturalmente marginal que es el cómic" (Witek, 1989, p. 13), tal vez resultase, como rezaba el eslógan de True Comics, "mil veces más emocionante que la ficción", pero disfrutó de una corta existencia porque también era "mil veces menos vendible" (Morris-Suzuki, 2005, p. 170), a excepción de la serie Classic Comics, inaugurada en 1941 y conocida a partir de 1947 como Classics Illustrated, sobre cuya relación con Alejandro Magno volveremos más adelante a propósito de sus versiones europeas. Por otra parte, el fallecimiento de Gaines en 1947 provocó la posterior reorientación de la editorial por su hijo William hacia temas de mayor éxito comercial como el terror o el crimen y la sustitución de un tratamiento descriptivo y ejemplarizante de la realidad por el sensacionalismo y la violencia hasta provocar en la década siguiente un creciente rechazo hacia los cómics que se plasmó en la cruzada emprendida por el psiquiatra 
Fredric Wertham para identificarlos como factor de perversión entre la juventud paralela a la del senador McCarthy contra el cine por esos mismos años (Serradilla, 2013)-, en las consiguientes recomendaciones del Subcomité del Senado sobre Delincuencia Juvenil en la primavera de 1954 y, finalmente, en la instauración oficial en ese mismo año de la "autorregulación" del género -autocensura, de hecho- a través del Comics Code Authority (Beaty, 2005; Fernández Sarasola, 2011; Mickwitz, 2014; Hajdu, 2018). En este contexto, durante la década de 1950 y los primeros años de la siguiente asistimos a la práctica desaparición del cómic educativo de temática histórica, cuyas escasas manifestaciones quedan relegadas a una posición casi exclusivamente anecdótica y, en consecuencia, reducidas a un espacio mínimo.

Resulta significativo en ese sentido el hecho de que el cómic más destacado de tema histórico y formato biográfico referido a Alejandro Magno no sólo en el contexto editorial estadounidense de esta época, sino incluso hasta el siglo XXI, se halle representado precisamente por la obra más extensa publicada hasta esa fecha entre las dedicadas a Alejandro -36 páginas- y, lo más importante, la primera editada como monografía independiente -y no dentro de una revista, bajo la forma de una o varias entregas y junto a otras historietas-, pero que, a pesar de todo ello, se limite a ser un producto subordinado a otro principal al que remite como resultado de una temprana estrategia de márketing transmedia. Editado por Dell Comics en 1956 (col. Four Color, serie 2, n. 688) con guión de Paul S. Newman y dibujo de Alberto Giolitti -y no de John Buscema, como se ha apuntado en ocasiones-, Alexander the Great. The boy who conquered the world constituye la adaptación gráfica de la película Alejandro Magno escrita, producida y dirigida por Robert Rossen ese mismo año ${ }^{18}$ y fue concebida como uno más de los elementos que, junto a ropa y joyas, integraron el merchandising de una producción cinematográfica a cuya promoción en Estados Unidos se destinó un millón de dólares y una publicidad sin precedentes: trece páginas en la revista Life, trescientas cuñas radiofónicas y múltiples anuncios a doble página en periódicos, así como desfiles callejeros de lanceros, danzarinas y elefantes ${ }^{19}$.

\footnotetext{
${ }^{18}$ Sobre la película de Rossen en el marco general de la presencia de Alejandro Magno en el cine, vid. Antela-Bernárdez y Prieto (2008), Prieto (2011) y Wieber (2008), y de manera específica Shahabudin (2010), Macarro (2015) y Blanshard (2018).

${ }^{19}$ Brooks (1956); Shahabudin (2010). Bajo el título Boy who took the world, el publirreportaje de Life (vol. 39, n.- 20, 14 de noviembre de 1955, pp. 79-102) puede ser consultado en https://books.google.es/books?id=ZVQEAAAAMBAJ\&pg=PA79\&dq=\%22alexander+the+great\%22\&hl=es \&sa=X\&ved=0ahUKEwjCiuDd-crlAhXF8uAKHWWGCskQ6AEIKDAA. La huella que dejó en el imaginario popular estadounidense perduró hasta el extremo de que la exposición The Search for Alexander inaugurada en 1981 en la National Gallery de Washington se abría con una presentación de siete minutos
} 
Como parte de semejante estrategia comercial, la publicación de este cómic por Dell editorial especializada en adaptaciones a este formato de obras cinematográficas y televisivas- apuntaba directamente a la promoción de la película en el ámbito escolar (Brooks, 1956). Ciertamente, la obra repasa la biografía del personaje, incluye en el reverso de la portada un mapa en blanco y negro del imperio de Alejandro e incorpora en la contraportada una "promesa" en la que garantiza a los adultos que compran el comic la transmisión de contenidos apropiados para sus hijos que van a leerlo ${ }^{20}$. Pero, en la medida en que se trata de la adaptación de la película - un hecho evidenciado no sólo en la incorporación de los créditos y dos fotografías de la misma en el reverso de la portada, sino incluso en la representación dibujada de Alejandro con los rasgos del actor protagonista, Richard Burton, y traducido, en consecuencia, en una pérdida de originalidad en tanto que creación artística y cultural-, su paralelismo con ella le hace compartir tanto sus cualidades como sus defectos, pues la aportación personal del director de la película y su apuesta por explicar la historia de Alejandro en función de la psicología del personaje y de la historia de Grecia -la acción se desarrolla fundamentalmente en Macedonia- limita enormemente el ritmo narrativo y desequilibra el relato histórico -los sucesos posteriores a Gaugamela se describen en apenas cinco páginas-. Con todo, esta obra ejercerá una influencia notable y la representación gráfica que muestra de Alejandro reaparecerá en otras publicaciones durante los años sucesivos.

No serán los Estados Unidos el único país en el que la promoción de la película impulse la publicación de una versión de la misma en cómic. La edición de Dell apareció en Gran Bretaña ese mismo año, publicada íntegramente por World Distributors como número 17 de la colección "A Movie Classic” y en versión resumida a través de las seis entregas semanales de Alexander the Great sin firma -una política editorial generalizada en el cómic británico de la época- entre abril y junio bajo la forma de una simple columna en media página en blanco y negro en la revista Express Weekly (p. 19 de los números 81-85, 1956, ed. Beaverbrook). Igualmente resumida -y

de duración a base de diapositivas que mostraban tanto el cómic de Dell como una foto del actor Richard Burton, protagonista de la película, según la reseña publicada el 12 de enero en la revista People titulada "Picks and Pans Review: The Search for Alexander": https://people.com/archive/picks-and-pans-reviewthe-search-for-alexander-vol-15-no-1/; vid. asimismo Nygard y Tomasso (2016).

20 "A PLEDGE TO PARENTS. The Dell Trademark is, and always has been, a positive guarantee that the comic magazine bearing it contains only clean and wholesome juvenile entertainment. The Dell code eliminates entirely, rather than regulates, objectionable material. That's why when your child buys a Dell Comic you can be sure it contains only good fun. 'DELL COMICS ARE GOOD COMICS' is our only credo and constant goal' (p. 36). 
desde una perspectiva más próxima a la aventura que a la historia, según Thiébaut (1999, p. 146)- es la versión en cuatro páginas en color de Alexandre le Grand (réalisé par Robert Rossen) que, con guión de Alain Bertrand y dibujo sin firma, aparecieron en diciembre de ese mismo 1956 en la sección "Notre film complet" de la revista semanal francesa Hurrah! (2. a serie, n.ํ 167, 29 de diciembre de 1956, ed. Les Publications Périodiques Modernes). Y en enero de 1957 la editorial Novaro publicó en México la versión de Dell traducida al español bajo el título Alejandro el Magno como número 2 de su colección mensual "Clásicos del Cine", sin incluir el mapa ni los créditos de la película en el reverso de la portada, pero con un equivalente del compromiso expresado por Dell acerca de lo adecuado de sus contenidos para el público infantil y juvenil, dirigido en este caso no sólo a los familiares, sino también a los docentes ${ }^{21}$.

Poco antes encontramos a Alejandro en historietas de extensión muy reducida publicadas en revistas de tema bélico en el marco, una vez más, de la participación estadounidense en diferentes conflictos y, en consecuencia, asociando implícitamente dicha participación con la figura del macedonio en tanto que paradigma del héroe militar victorioso en el combate ${ }^{22}$. Así, en el contexto de la Guerra de Corea encontramos aproximaciones biográficas al personaje muy simplificadas en las seis páginas de Alexander the Great, de Sid Check (Battle Action, n.․ 11, abril de 1953, ed. Newsstand Publications Inc.), centradas exclusivamente en su caracterización militar y en la negativa influencia de su madre Olimpíade -caracterizada (leopardo incluido) como la Popea de la película Quo Vadis dirigida por Melvin LeRoy y estrenada apenas dos años antes-, y en las cinco de Alexander the Great!, de C. A. Winter (Battle, n.ำ 30, junio de 1954, ed. Foto Parade), cuyo estilo expresionista contrasta con un afán didáctico que impone abundantes textos explicativos a un diálogo casi inexistente e incorpora un mapa del Imperio de Alejandro con quince ubicaciones de ciudades y batallas en la leyenda (p. 3). Se trata de una imagen que, dentro de este mismo tipo de revistas, todavía reaparecerá durante la Guerra de Vietnam, aunque con una extensión aún más limitada, de cuatro páginas para presentar al personaje como el

\footnotetext{
21 “UN ATENTO MENSAJE A PADRES DE FAMILIA Y MAESTROS. La banderita dentro del triángulo blanco que aparece en la parte superior izquierda de nuestras revistas es símbolo de calidad, moralidad y originalidad. En la edición de las revistas ponemos especial cuidado a fin de que su contenido, tanto en las ideas como en la forma de expresarlas, esté apegado a la ética más estricta y constituya, a la vez, material de ameno entretenimiento, interesante lo mismo para niños y jóvenes, que para adultos" (p. 36).

22 Sobre el cómic norteamericano de tema bélico como vía tanto para reflejar como para promover sentimientos -desde el patriotismo hasta la protesta- en la sociedad de Estados Unidos durante períodos de conflicto, vid. Scott (2011).
} 
héroe que proporciona la victoria a Macedonia en Chaeronaea!, de Ric Estrada (Our Army at War, n. ${ }^{\circ}$ 216, marzo de 1970, ed. DC, dentro de la sección "The Great Battles of History" y junto a otras como Kadesh, Roncesvalles, la derrota de la Gran Armada o el Marne), e incluso de una sola en Alexander, con texto de Raymond Marais y dibujo

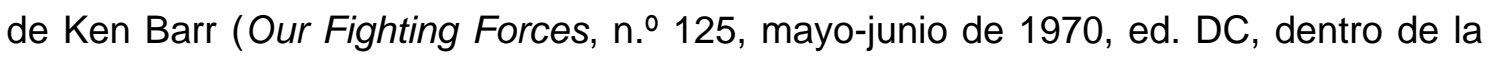
sección "Warrior. History's Mightiest Men of Combat!" y junto a personajes como Tutmosis III, Atila, Gengis Kan, Napoleón, Pontiac o Eisenhower) ${ }^{23}$. Sin embargo, más allá de ese subgénero, tan sólo contamos con referencias de carácter puramente informativo y extensión mínima, como la simple viñeta que se le dedica en cada caso a propósito de la doma de Bucéfalo en la única página de la sección "They Were Great" del único número que llegó a publicarse del cómic de tema histórico Conquest (1955, ed. Eastern Color Printing $)^{24}$ y en relación con su protagonismo histórico como conquistador en la igualmente única viñeta de "They Ruled the World" firmada por Gaylord DuBois en el volumen Master of the World (1961, ed. Four Color), o las asociadas al tratamiento didáctico de temas como la fauna, la geografía y los inventos incluidas en revistas del tipo The World Around Us, Treasure Chest of Fun and Fact, Showcase y Mickey Mouse durante finales de la década de 1950 y comienzos de la siguiente ${ }^{25}$.

\footnotetext{
${ }^{23}$ Este tipo de revistas incorporan igualmente la figura de Alejandro en historietas ya no de tema históricobiográfico, sino puramente ficcional, como la serie The Haunted Tank, que muestra al personaje en el más allá asignando a otro famosos líderes militares de la Historia la misión de velar por heroicos combatientes durante la Segunda Guerra Mundial en las historietas The Battle Origin of the Haunted Tank, con guión de Robert Kanigher y dibujo de Russ Heath (G.I. Combat, n.- 114, octubre-noviembre de 1965, ed. DC Comics), Some Generals never learn! (ibid., n.․ 256, agosto de 1983) y Death March (n. .274 , febrero de 1985), las dos últimas con guión de Robert Kanigher y dibujo de Sam Glanzman (O'Connor, 2015). La serie reaparece en ediciones posteriores asociada a la participación norteamericana en los conflictos de Irak (ed. Vertigo, 2009) y Afganistán (ed. DC Comics, 2012-2013), si bien en ellas ya no aparece Alejandro Magno.

${ }^{24}$ La obra puede ser consultada en http://comicbookplus.com/?dlid=20386.

${ }^{25}$ En un formato similar a una temprana viñeta dedicada a Alejandro a propósito de la estandarización de los sistemas de medida en el comercio antiguo y publicada en The Amazing Story of Measurement (1949, ed. The Lufkin Rule Co.) se presentan posteriormente las asociadas con Bucéfalo en "Heroic Horsemen" (The Illustrated Story of Horses - The World Around Us, n.․ 3, noviembre de 1958, p. 62; ed. Gillberton); con el paso del Hindu Kush en "Conquering the Barriers" (The Illustrated Story of High Adventure - The World Around Us, n. .27 , noviembre de 1960, p. 20); con la invención del submarino a propósito del episodio transmitido por la tradición novelística de Alejandro en "Underwater Conquest" (Undersea Adventures - The World Around Us, n. ${ }^{\circ}$ 30, febrero de 1961, p. 15), en "Submarine" (Treasure Chest of Fun and Fact, vol. 19, n.․ 6, 1963, p. 29, ed. Catechetical Guild Educational Society: http://comicbookplus.com/?dlid=59213) y en "The Divers of Olde" (Showcase, 29, diciembre de 1959, p. 20, ed. DC); de nuevo con los sistemas de medida en "Men, the Measuring Tape" (Treasure Chest of Fun and Fact, vol. 12, no 14, 1957, p. 11: http://comicbookplus.com/?dlid=36098); y con los sistemas de espionaje en el capítulo "From Moses to Madrid" de Spies (The World Around Us, n.. 35 , agosto de 1961, p. 10) y en "Secret Messages - Codes and Ciphers" (Mickey Mouse, n.. 108, agosto de 1966, ed. Western).
} 
De hecho, por lo que resta de siglo, frente al protagonismo que conserva e incluso acrecienta en el cómic de tema ficcional (Pelegrín Campo, 2019, pp. 378-380) y junto a las páginas en blanco y negro que le dedica Larry Gonick en su aproximación generalista The Cartoon History of the Universe: From the Big Bang to Alexander the Great (vol. 7, 1978, pp. 46-48, ed. Broadway Books), de la presencia de Alejandro en el cómic de tema histórico sólo cabe destacar las dos en color de The Kutim, de Joe Kubert, publicadas en la revista mensual Moshiach Times (vol. 2, n. 8, agosto de 1985), que evocan un episodio según el cual Alejandro supuestamente habría reconocido al sumo sacerdote del templo de Jerusalén como el anciano que anteriormente se le había aparecido en sueños para anunciarle la victoria en todos sus proyectos $^{26}$. Esta breve historieta forma parte de una serie más amplia protagonizada por Jacob e Isaac, hermanos y estudiantes en una escuela talmúdica que repasan diferentes episodios históricos en los que se destacan precisamente valores y personajes de su tradición religiosa, y debe ser entendida en el contexto de las disputas entre judíos y samaritanos, desde la perspectiva del judaísmo ortodoxo y con una evidente finalidad didáctica y moralizante, hasta el punto de que la posterior recopilación de la serie en el volumen The Adventures of Yaakov and Isaac (Jerusalén: Mahrwood Press, 2004) incluye comentarios de carácter didáctico redactados por el propio Kubert a modo de introducción a cada historieta. En este caso la positiva presentación de Alejandro se halla exclusivamente asociada a su intervención como defensor de los valores religiosos judíos tradicionales, en una imagen tan particular como aislada que no hace sino actuar a modo de epílogo de la aproximación históricodidáctica a la figura del macedonio en el cómic de los Estados Unidos durante el siglo $\mathrm{XX}$.

\section{Alejandro Magno en el cómic didáctico europeo del siglo XX}

En Europa el cómic quedó etiquetado desde muy temprano como producto destinado al público infantil y juvenil. Fue precisamente el temor existente a la influencia que sobre los más jóvenes podían ejercer los cómics norteamericanos lo que, desde ámbitos muy próximos a la Iglesia Católica, inspiró el nacimiento de revistas dotadas

\footnotetext{
${ }^{26}$ El episodio es transmitido por las Antigüedades judías de Flavio Josefo (XI 326-339) y por el Talmud (Yomá 69a); sobre la cuestión de su historicidad, vid. Ben Sahar (2018).
} 
de un tono edificante y aleccionador como la francesa Cœurs Vaillants en 1929 (editada por la Union des CEuvres Catholiques de France) y posteriormente las belgas Le Journal de Spirou en 1938 y Le Journal de Tintin en 1946 (Delisle, 2010) y culminó en Francia con la promulgación de la ley de 1949 sobre las publicaciones destinadas a los jóvenes, impulsada no sólo por los sectores más conservadores, sino también por el Partido Comunista, que identificaba el cómic norteamericano como una muestra de la colonización cultural practicada por el capitalismo (Ory, 1984; Fernández Sarasola, $2011)^{27}$. Paralelamente, en España tras la Guerra Civil este tipo de publicaciones no contaron con una regulación específica hasta la creación en 1952 de la Junta Asesora de la Prensa Infantil, pero no faltaban voces que reclamaran esa regulación precisamente por la utilidad de esas revistas como herramienta didáctica ${ }^{28}$. Así, en 1941 fray Justo Pérez de Urbel, director de Flechas y Pelayos desde 1938, consideraba que

\begin{abstract}
"la revista infantil, (...) complemento de la escuela, debe también ella tener como finalidad primaria la formación. (...) el héroe de una historieta puede despertar sentimientos y sugerir ideas de moralidad (...); en moral, derramad los grandes principios en cuentos e historietas cuyos héroes sean los prototipos de la audacia, del valor, de la piedad, de la compasión, del amor a la patria, de los sentimientos nobles y generosos. (...) Si esa generación (...) se despertó a la vida, al ímpetu, a la hazaña, al honor del trabajo, recordando a los conquistadores de mundos, a los colonizadores insignes, a los sembradores de civilización y de luz, héroes gigantes, pero de carne y hueso, reales, nuestros, entonces esa generación tendrá una fuerza, una riqueza interior, un hálito misterioso que la hará superior a todas las dificultades y a todos los peligros" (Pérez de Urbel, 1941, pp. 56 y 57-58).
\end{abstract}

Éste será el horizonte que contemple la aparición de Alejandro Magno en el cómic europeo, un fenómeno cuya primera manifestación tendrá lugar precisamente en España.

\footnotetext{
${ }^{27}$ La ley de 1949 propició la creación de la Comisión de vigilancia y de control de las publicaciones destinadas a la infancia y a la adolescencia, encargada de velar por que dichas publicaciones no incluyesen "ninguna ilustración, ningún relato, ninguna crónica, ningún título, ningún anuncio que presente bajo una luz favorable el bandolerismo, la mentira, el robo, la pereza, la cobardía, el odio, el libertinaje o todos los actos calificados como crímenes o delitos o de naturaleza para desmoralizar a la infancia o la juventud, o para inspirar o mantener prejuicios étnicos" (Loi n. 49-958 du 16 juillet 1949 sur les publications destinées la jounesse: https://www.legifrance.gouv.fr/affichTexte.do;jsessionid=325768B809F1C19F34F681C37E59D37E.tplgfr3 3s 2?cidTexte=JORFTEXT000000878175\&dateTexte=20100710); vid. al respecto Méon (2009).

28 En la práctica estas publicaciones se vieron muy limitadas desde 1941 por la necesidad de ser reconocidas oficialmente como publicaciones periódicas por la Vicesecretaría de Educación Popular de FET y de las JONS -incorporada en 1945 como Subsecretaría al Ministerio de Educación Nacional- para poder disponer de un título de colección, de una numeración propia y, sobre todo, de la subvención del papel para ser editadas (Fernández Sarasola, 2013).
} 
Alejandro Magno en el cómic didáctico español ${ }^{29}$

En el marco así definido por Pérez de Urbel -que, prescindiendo de su particular carga ideológica, en términos didácticos comparte el planteamiento defendido en esas mismas fechas por Clara S. Littledale a propósito del cómic educativo en Estados Unidos-, dentro del cómic español de la época hallamos episodios históricos identificados con gestas patrióticas por el régimen de Franco como el asedio de Sagunto, la conquista de Granada, la batalla de Lepanto o la Guerra de la Independencia en la colección "Selección Aventurera" (ed. Valenciana, 1941), la conquista de América en "Las Grandes Aventuras" (ed. Hispano Americana, 1941) y Viriato, Numancia o el sitio de Zamora en "Heroicos episodios de la historia de España" (ed. Marco, 1943), presentados todos ellos desde los esquemas de la aventura clásica (Porcel, 2010). Sin embargo, entre los cuadernos de la colección "Aventuras célebres" publicados en 1942 por la editorial Cisne, junto a temas coincidentes con los ya citados -la conquista de América a través de la figura de Alonso de Ojeda en Un hombre audaz y los Tercios de Flandes en Un capitán heroico, ambos de Tomás Porto- y versiones de novelas clásicas de aventuras, encontramos Lucha a muerte y El jinete invencible, ambos con dibujo de Luis (Luis Enrich Font) y dedicados respectivamente a Aníbal y a Alejandro Magno en tanto que personajes históricos cuyas hazañas los equiparaban de facto tanto con los protagonistas de las más apasionantes aventuras como con el héroe modélico que reclamaba Pérez de Urbel $^{30}$. En formato apaisado $(17 \times 25 \mathrm{~cm})$ y con ocho páginas en blanco y negro además de las cubiertas en color, El jinete invencible constituye, de hecho, el primer cómic europeo protagonizado por Alejandro Magno del que tenemos noticia ${ }^{31}$. Con un claro predominio de los textos explicativos frente a los diálogos y un dibujo muy plano y lineal pero, a la vez, muy dinámico y en el que a menudo las figuras superan el límite

\footnotetext{
${ }^{29}$ Una parte de esta sección ha sido presentada como comunicación en el II Congreso Internacional de Estudios Interdisciplinares sobre el Cómic (Zaragoza, 15-17 de mayo de 2019) (Pelegrín Campo, en prensa).

${ }^{30}$ De igual modo, en la misma colección El triunfo de la verdad, de Juan B. Oché, narra la leyenda de Havelock el danés. Años más tarde fueron reeditados en la revista El Coyote -publicada por Ediciones Clíper, propiedad del mismo editor que Cisne- tanto Un hombre audaz (n.- 24, 1948, pp. 14-15, y n.. 25 , 1948, pp. 18-19) y Un capitán heroico (n.․ 29, 1948, pp. 18-19, y n.․ 30, 1948, pp. 18-19) como Lucha a muerte (n. $.34,1949$, pp. 10-12).

${ }^{31}$ Agradezco a la Biblioteca Nacional de España la disponibilidad para consultar a través del servicio de fotodocumentación el ejemplar conservado entre sus fondos (http://datos.bne.es/edicion/a4674724.html).
} 
de sus propias viñetas e incluso invaden los bocadillos de las inmediatas ${ }^{32}$, la obra presenta la figura de Alejandro Magno en tanto que modelo del héroe conquistador y desde una perspectiva exclusivamente biográfica -ajena, en consecuencia, a cualquier asociación con elementos fantásticos o ficcionales y, en este sentido, característica del tratamiento del personaje en el cómic español ${ }^{33}$ - aunque extremadamente resumida por hallarse limitada a los episodios de la doma de Bucéfalo y las batallas de Gránico, Issos y Gaugamela.

Junto al cuadernillo de aventuras, la figura de Alejandro vuelve a aparecer en el cómic español en las revistas infantiles humorísticas -formatos ambos propios de esos años y de los que les siguieron (Porcel, 2011)-, y un año más tarde, en 1943, entre artículos literarios, viñetas e historietas la revista Atalaya publicó semanalmente desde enero a mayo (números 161-181) una tira vertical dibujada por Ramón Sabatés -más conocido como autor de la serie Los grandes inventos del TBO- que, siempre integrada por tres viñetas en blanco y negro sin marco delimitador ni diálogos y con dibujo muy sencillo y texto explicativo al pie, presenta con un tono moralizador una biografía de Alejandro desde su infancia hasta su muerte, acaecida ésta "después de un banquete en que había comido desmesuradamente", pues "sus vicios le condujeron rápidamente al sepulcro" (n. ${ }^{\circ} 181$, p. 326).

En los años que siguen será este segundo formato el que predomine de acuerdo con la misma fórmula dominada por la presencia de párrafos explicativos, carente de diálogos, puramente descriptiva, escasamente dinámica y de extensión muy reducida: en su mínima expresión en una breve tira firmada por Ripoll G. (Miguel Ripoll Guadayol) y asociada exclusivamente al episodio del nudo gordiano con tan sólo tres imágenes en blanco y negro y dos párrafos explicativos que se publicó en la revista Leyendas infantiles (n. 137, p. 11, 1946, ed. Hispano Americana de Ediciones); en una

\footnotetext{
${ }^{32} \mathrm{Y}$ ello a diferencia de las adaptaciones literarias recogidas en la misma colección, las cuales "no son evidentemente tebeos didácticos, aunque el aire formal y envarado que preside las adaptaciones así parece indicarlo. Todo es como muy serio ya desde las portadas, que rehúyen la representación de escenas sensacionales para centrarse en motivos casi costumbristas" (Porcel, 2010, p. 91).

${ }^{33}$ La única ocasión de la que tenemos noticia en la que a lo largo del siglo XX -y, de hecho, hasta la publicación en 2010 de La Ciudad Oculta de Alejandro Magno, de Jordi Bayarri (ed. Viaje a Bizancio ediciones)- un cómic español introduce a Alejandro en una trama de carácter ficcional la proporciona el número doce de la serie de viajes en el tiempo Anceo, titulado El Magno (Macedonia) (1980, ed. Polen), con dibujo en blanco y negro y portada en color de Alberto Marcet y, como se indica en la primera viñeta, guión de A. Dubar (si bien según informaciones recogidas en http://www.autoresdecomic.com/Autores/Marcet/Archivos/News.html se trataría de "Augusto Dybar", pseudónimo de Agustín Riera, y con Marcet habría colaborado su hijo Manuel Ángel) (Pelegrín Campo, en prensa).
} 
página integrada por seis ilustraciones en blanco y negro de Alfredo lbarra acompañadas por sendos párrafos explicativos que, tras la presentación, abordan el destino de Alejandro, la destrucción de Tebas, el nudo gordiano, la conquista de Asia y la muerte del personaje dentro de la sección "Galería de nombres famosos" de la revista Galerías Preciados (n. 9 9, 1953, p. 7, ed. Galerías Preciados), que se entregaba como obsequio a los clientes de los grandes almacenes del mismo nombre -lo mismo que los primeros cómics norteamericanos hasta la publicación de Famous Funnies (vid. supra)-; y en una brevísima viñeta moralizante con texto basada en un pasaje de Plinio el Viejo ( $N H$ XXXV 85) acerca de cómo, a diferencia de Alejandro en el estudio del pintor Apeles, no se debe hablar de lo que no se sabe, viñeta recogida en la revista infantil Molinete (.$^{\circ} 2$, año II, 1958, p. 13) que editaba la Institución Teresiana, en cuyos colegios e instituciones afines era distribuida -al igual que antes Cœurs Vaillants en Francia-; y en la biografía Alejandro Magno: la forja de un imperio, de Federico Blanco, publicada en Capitán Trueno. Almanaque para 1960 (1959, pp. 32-33, ed. Bruguera), cuyas dos páginas en blanco y negro se centran casi exclusivamente en los episodios bélicos y, a la vista del yelmo y de la coraza de escamas triangulares que porta el protagonista, con ecos de la película de Rossen, rodada en España y estrenada en 1956, o bien de la versión en cómic de la misma que, como hemos apuntado más arriba, había sido publicada por Dell Comics ese mismo año y traducida al español en México por Novaro en 1957.

En todos estos casos lo limitado del formato utilizado condiciona la incorporación ya no sólo de cualquier tipo de recurso didáctico, sino incluso de un volumen mínimo de información, y, en consecuencia, da lugar a aproximaciones incompletas y a menudo meramente anecdóticas. De ahí el mayor interés que presenta el formato del cuaderno de aventuras por entregas utilizado para editar la primera biografía por extenso de Alejandro Magno en un cómic español, representada por los cuatro episodios que integran la serie Alejandro Magno dentro de la colección "Héroes y maravillas del mundo", con guión de Joaquín Berenguer Artés y dibujos de Juan Martínez Osete (ed. Marco, 1954), titulados sucesivamente Sangre de conquistador, La falange invencible, Asedio a Tiro y La última batalla. Cada uno de ellos consta de doce páginas apaisadas de $22 \times 27 \mathrm{~cm}$, las cuales, exceptuando la portada -la única en color-pero incluyendo la contraportada -en tinta azul y con el consabido rótulo "Leed el próximo episodio" en los tres primeros-, se estructuran generalmente en cuatro filas repartidas en cuatro 0 cinco viñetas y alguna didascalia para mostrar una narración muy ágil, característica del cómic de aventuras, vertebrada fundamentalmente por los diálogos encerrados en 
bocadillos y biográficamente mucho más completa que en los casos anteriores por cuanto repasa buen número de los episodios históricos protagonizados por Alejandro y a pesar de detalles como una indumentaria militar de macedonios y griegos que resulta excesivamente romana.

Precisamente ese formato propio del cómic de aventuras es el que incorpora a partir de 1955 la editorial Bruguera cuando en los volúmenes de su colección "Historias" inaugura una nueva fórmula narrativa que alterna tres páginas de texto y una de cómic en una doble narración -literaria y gráfica- de la misma historia, paralela pero independientemente. Esta fórmula será utilizada en las décadas siguientes para narrar la biografía de Alejandro: por vez primera en Alejandro el Magno, obra publicada por la editorial Ferma con texto de Salvador Dulcet y dibujo en blanco y negro de Tello ("Colección Juvenil Ferma", n. 25, 1960); después, por las tres ediciones sucesivas que la propia Bruguera lanzó de Alejandro Magno, con texto de Joseph Lacier (pseudónimo de José Ripollés Aguilar) y dibujos en blanco y negro de Carlos Campañá Salas (la primera en "Colección Historias", n. ${ }^{\circ} 150,1962$, y las siguientes en “Colección Historias Selección", serie "Historia y biografía”, n. 30, 1967 y 1974, con paginación independiente para la parte gráfica) ${ }^{34}$; y finalmente por la editorial Toray en sus sucesivas colecciones "Hombres famosos", cuando el cómic Alejandro Magno. Conquistador de Asia editado en 1968 como cuaderno grapado con otro guión de Salvador Dulcet y dibujo bicolor de Antonio Borrell (n.9 9, con portada de Rafael Cortiella) se convirtió en 1977 ( $n .$. 12, portada de Bosch Penalva) y en 1991 (n. 8 , portada de Carlos Prunés) en sendos volúmenes en tapa dura que alternaban de manera irregular las páginas del citado cómic -ahora en blanco y negro- con las del texto firmado por S. Pascual (Enrique Sánchez Pascual). A pesar de la originalidad y el dinamismo de la fórmula, el ritmo narrativo se resiente, pues la versión gráfica no hace sino resumir la literaria y los textos de los bocadillos apenas hacen otra cosa que confirmar lo apuntado en las cartelas explicativas, excepto en el caso de Toray, en el que el cómic precedió al texto literario y los diálogos se suceden a lo largo de varias viñetas, si bien incurre en errores de cronología al situar la batalla del Gránico tras el

\footnotetext{
${ }^{34}$ Esta obra alcanzó cierta difusión y su parte gráfica fue publicada en Bélgica ese mismo año en francés como Alexandre le Grand en la revista Samedi Jeunesse (n.․ 62, diciembre de 1962, 34 pp. con numeración propia) y al año siguiente en flamenco como Alexander de Grote en Ohee! (n. ํ 14, 20 de julio de 1963, ed. Het Volk), mientras que en 1970 fue publicada completa en este último idioma (col. "HeroïcaBibliotheek", n. ${ }^{\circ} 58$, ed. D.A.P. Reinaert Uitgaven); vid. asimismo infra, n. 43.
} 
episodio del nudo gordiano y el matrimonio con Roxana tras la victoria del Hidaspes, y atribuye el retorno a Babilonia desde la India exclusivamente a la vía marítima.

Todavía encontraremos la tradicional fórmula de viñetas carentes de diálogo acompañadas por textos explicativos al pie en Alexander, de Jesús Blasco -el primer ilustrador español que trabajó en el Reino Unido-, publicado originalmente en inglés en la revista Tell Me Why en 1968 (números 13 y 14, ed. Fleetway, que desde 1962 editaba el semanario didáctico juvenil Look and Learn), en francés como Alexandre le Grand en el semanario Je sais tout al año siguiente (n.ำ 2, sección "Destins horssérie", ed. Édi-Monde) y posteriormente en España como Alejandro el Grande en la revista Chito (números 1 y 2, 1974, ed. Juan Martí Pavón). Se trata de un repaso de la biografía del conquistador a través de la presentación de los episodios más importantes en una sucesión de dieciséis viñetas en color de enorme calidad artística, pero la rigidez y falta de dinamismo propias de esta fórmula característica de cómics de épocas pretéritas y más próxima al texto ilustrado que al cómic encuentran en la obra de Blasco una de sus últimas muestras, en claro contraste con las nuevas tendencias del momento ${ }^{35}$.

Y es que, con los nuevos tiempos y al igual que en otros países europeos, llegará la progresiva desaparición de las revistas en las décadas de 1970 y 1980 y su sustitución por los álbumes. En ocasiones éstos se agrupan en series de aventuras protagonizadas por diferentes personajes, como la serie "Cómic Biografías", editada en color por Bruguera en 1984 bajo la forma de cuadernillos poco después reunidos en

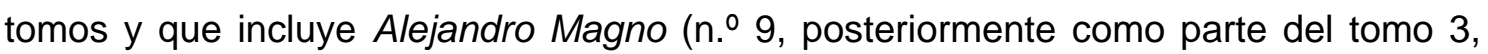
Serie Historia), con guión de Alejandro Montiel, dibujos de José María Martín Saurí e ilustraciones de la cubierta a cargo de Bosch Penalva ${ }^{36}$. La obra repasa los acontecimientos más importantes y conocidos de la vida del protagonista a través de una cuidadosa ambientación, inspirada en fuentes tanto literarias como arquitectónicas y cerámicas, y que incluye el uso de mapas históricos tanto para ubicar geográficamente la acción como para distinguir entre las diferentes etapas que

35 La obra puede ser consultada en Díez (2009) y en la entrada de blog http://arje1eso.blogspot.com/2011/01/alejandro-magno-el-magno-por-jesus.html, creada el 22 de enero de 2011 por "Antonio", docente de Educación Secundaria, con la finalidad de proporcionar a su alumnado de Geografía e Historia de 1. de ESO actividades y recursos sobre los contenidos referidos a la Historia de la Grecia antigua.

${ }^{36}$ Desde aquí deseo expresar mi mayor agradecimiento para con Alejandro Montiel y José María Martín Saurí por la amabilidad y cordialidad que me mostraron en todas nuestras comunicaciones. 
articulan la narración -la situación inicial (p. 1), la conquista hasta la llegada a Egipto (p. 12) y el retorno a Babilonia (p. 27)-. A ello se suma un grafismo muy particular que combina iconografía clásica y barroquismo modernista, a caballo entre el art nouveau y el pop, en la que el uso de sombras y claroscuros acentúa la profusión de cuerpos desnudos -masculinos y femeninos- mostrados en posturas y actitudes lánguidas que lo aproximan al clasicismo prerrafaelita de Lawrence Alma-Tadema y entre los que un Alejandro hiper(bi)sexualizado -cuestión nunca antes reflejada en un cómic- aparece representado más en los banquetes que en la batalla, reflexivo hasta lo melancólico, incluso vulnerable, en contraste con la magnitud de su poder y la extensión de sus conquistas. Toda una definición de la crisis introspectiva del héroe considerado paradigma del conquistador -plasmada en una imagen muy próxima a la que de su protagonista transmite otra obra inmediatamente anterior del mismo dibujante, Odiseo / The Odyssey, con texto de Francisco Pérez $\mathrm{Navarro}^{37}$-, que contrasta radicalmente con todo lo visto hasta el momento por cuanto refleja en última instancia la transformación cultural de la sociedad española al final de la Transición. De hecho, llama la atención la reedición de esta historieta dos años más tarde en un número de la serie Mortadelo Especial (n.- 202, titulado Tele Telele, 1986, pp. 36-65), un tipo de revista en la que poco antes hubiese resultado impensable encontrar una obra semejante. Este hecho constituye una señal inequívoca de que en España los tiempos habían cambiado: hasta tal punto que en esa misma década la figura de Alejandro Magno abandonará el cómic por el libro-álbum hasta ya entrado el siglo XXI.

\section{Alejandro Magno en la bande dessinée didáctica franco-belga}

Con cierto retraso respecto a la iniciativa española, la bande dessinée franco-belga muestra su primera versión gráfica de nuestro personaje en Alexandre le Grand, con texto de Octave Joly y dibujos de Dino Attanasio, a lo largo de cuatro páginas -la primera y la última en color, las centrales en blanco y negro- publicadas en la revista Le Journal de Spirou (n. $.^{674}, 15$ de marzo de 1951, pp. 5-8) dentro de la sección "Les

\footnotetext{
${ }^{37}$ Las ocho entregas de esta obra fueron publicadas casi paralelamente en español bajo el título Odiseo en la revista Comix Internacional (números 25-32, diciembre de 1982 - julio de 1983) y en inglés como The Odyssey en Heavy Metal (números 73-80, abril-noviembre de 1983) y posteriormente agrupadas en un solo volumen, editado primero por Planeta-DeAgostini en 1995 bajo el título Odiseo y más tarde por Norma Editorial como La Odisea en el blanco y negro original en 2007 (con motivo del vigésimoquinto aniversario de su aparición) y en color con entintado de Esther Sanz en 2014. Vid. al respecto Jenkins (2011) y Moula (2012).
} 
belles histoires de l'oncle Paul". A partir de ese mismo 1951 y durante más de treinta años dicha sección iba a presentar al personaje del tío Paul, un adulto de edad madura elegantemente vestido y fumador de pipa, erudito y reflexivo, pero próximo y afable, que aprovechaba cualquier comentario de sus sobrinos Arthur y Fred para ilustrarles $-\mathrm{y}$, con ellos, al lector- acerca de un personaje, un acontecimiento histórico, un descubrimiento o un invento (Pierre, 1979). En esta séptima entrega el propósito didáctico se acentúa en la medida en que la acción presenta a los chicos realizando sus deberes escolares y lamentando lo aburrido que resulta estudiar Historia, unas quejas que su tío combate recuperando el clásico argumento del cómic educativo norteamericano según el cual "la historia (...) es tan apasionante como una novela", pues “jtambién tuvo sus cow-boys! (...) Uno de los más famosos es ciertamente Alejandro el Grande" (p. 5) ${ }^{38}$. El desarrollo de esta analogía a partir del episodio de la doma de Bucéfalo le permite captar la atención de su auditorio y trasladar la acción al pasado para presentar de manera muy original la biografía del protagonista al prescindir casi por completo de las batallas -a las que dedica tan sólo una viñeta- y seleccionar otros pocas veces evocados en los cómics -la consulta al oráculo de Delfos, la distribución de sus bienes antes de marchar hacia Asia, la confianza en el médico Filipo, la respuesta a los consejos de Parmenión, la cesión del agua a sus soldados en el desierto de Gedrosia- hasta finalizar con la moraleja "Frente a la muerte, ¿de qué le sirvieron sus conquistas? (...) Dura lección, ¿no es cierto?” (p. 8) ${ }^{39}$.

En adelante este tipo de aproximación histórico-didáctica de extensión generalmente reducida a entre cuatro y seis páginas se generaliza entre los semanarios más populares de la bande dessinée, y particularmente en secciones como las "Histoires complètes didactiques" de Tintin y "Les plus belles histoires de l'oncle Paul" de Spirou (Thiébaut, 1999, pp. 86-112; Verreth, 2005, pp. 3-4). Algunas de estas obras abordan de manera tan general como apresurada la biografía de Alejandro bajo el título común Alexandre le Grand, como hacen las cuatro páginas en color de Fred y Liliane Funcken

\footnotetext{
${ }^{38}$ Resulta inevitable asociar con este comentario la viñeta realizada por Achdé -autor de los dibujos de Lucky Luke tras la muerte de Morris- con motivo de su asistencia a la Comic Con celebrada en Tesalónica del 5 al 7 de mayo de 2017 y en la que presenta al famoso vaquero admirado ante la estatua ecuestre de Alejandro Magno que desde 1974 se erige en el puerto de dicha ciudad y dirigiéndose a su caballo, igualmente admirado, para decirle: "Mi viejo Jolly Jumper, jeso es un cowboy!" (https://www.protagon.gr/epikairotita/einai-o-megas-aleksandros-kaouboi-44341403892).

39 Una fórmula similar se aplicará en la revista española Ocurrió una vez... (ed. Toray, 1958), cuyos números siempre se estructuran en torno a una aventura creada por Boixcar (Guillermo Sánchez Boix) narrada con un tono ejemplarizante ante un grupo de niños por el señor Peralta, "un hombre algo mayor, grueso, con bigote y mucha labia", a base de "exempla en los que esconde una lección moral tras un juego elaborado con arquetipos y personajes del género aventurero" (Porcel, 2010, p. 354).
} 
publicadas en Tintin tanto en su edición belga ( $n$. 50, 12 de diciembre de 1956; reed. en Les meilleurs récits de... Funcken, vol. 47, ed. Hibou, 2018, pp. 3-6) como en la francesa (n.. 431, 24 de enero de 1957, dentro de la sección "Histoires complètes didactiques"), en las que nada se dice de personajes como Roxana o Poros; la ya mencionada adaptación del film de Rossen publicada en la sección "Notre film complet" de Hurrah! (2. a serie, n.ำ 167, 29 de diciembre de 1956, ed. Les Publications Périodiques Modernes); las doce páginas en blanco y negro y en petit format (13 x 18 cm) firmadas por Gianni De Luca en Plutos (segunda serie, n. 24, diciembre de 1958; reed. en Mustang, $\mathrm{n}$. 0 3, marzo de 1967, 128-139; vid. Thomassian, 2018a, p. 55) caso este último en el que la influencia de la citada película se manifiesta ya no sólo en la representación del personaje con los rasgos del actor Richard Burton y con el yelmo y la coraza de placas triangulares ya mencionados, sino incluso en la incorporación de viñetas que reproducen escenas de la misma (así Alejandro ante su ejército [p. 132] o sentado en el trono del Gran Rey [p. 136])-; y las cuatro en bicolor de Guy Mouminoux publicadas en Cœurs Vaillants (n. ${ }^{\circ}$ 34, 26 agosto de 1962, pp. 811; reed. en blanco y negro en Samedi Jeunesse, n.ำ183, enero de 1973, pp. 37-40), que en tan breve espacio repasan apresuradamente algunos de los episodios más conocidos de la vida del conquistador -si bien sitúa en el desierto de Egipto y no en el de Gedrosia aquel en el que Alejandro rechazó beber agua si sus soldados no la tenían- ${ }^{40}$. Otras se centran en episodios concretos de esa biografía, y así L'éléphant fidèle, con guión de Octave Joly y dibujo de Robert (Spirou, n.ำ 1404, 11 de marzo de 1965, pp. 38-41, sección "Les plus belles histoires de l'oncle Paul"), evoca la inteligencia y valentía demostrada por el elefante de Poros en la batalla del Hidaspes según la noticia transmitida por Plutarco en su Vida de Alejandro ( $L X 7$, con mención incluida de este autor y nota explicativa al pie en la p. 40); Alexandre le Grand, de André Semal (Spirou, n.. 1555, 1 de febrero de 1968, pp. 12-15, sección "Spirou donne une chance aux jeunes"), aborda la misma batalla; À quinze ans, Alexandre dompte Bucéphale, con texto de Octave Joly y dibujo de Jean-Claude Pascal (Spirou, n. ํ 1576, 27 de junio de 1968, pp. 44-48, sección "Les plus belles histoires de l'oncle Paul"), repasa los episodios de la vida de Alejandro protagonizados por Bucéfalo, desde su doma en Macedonia hasta su muerte en la India; y Philippe et Alexandre. Le

\footnotetext{
${ }^{40}$ A ellas se suman las ilustraciones de Pierre Le Goff acompañadas de texto al pie -fórmula compartida con el Alexander de Jesús Blasco publicado un año antes y citado más arriba- que integran Alexandre le Grand contre Darius III Codoman en el marco del "Pilotorama" Arbèles: Alexandre défait l'armée perse (Pilote, n. 97, pp. 22-25 y 28-29, 15 de mayo de 1969, ed. Dargaud).
} 
déclin d'un faucon et l'envol d'un aigle, con texto de Laymilie (Jean-Luc Vernal) y dibujo de Jean Torton (“J. et A. Torton" en los créditos, p. 9), publicado en Tintin tanto en su edición belga (n. 4, 26 de enero de 1971, pp. 9-15, Éditions du Lombard; reed. en Les meilleurs récits de... Torton / Vernal, vol. 57, 2020, ed. Hibou) como en la francesa (n. $.1161,28$ de enero de 1971, ed. Dargaud Paris), presenta a un Alejandro que, todavía en vida de Filipo, demuestra su valor frente a Perinto y a los tracios y sueña con dominar Egipto. $Y$ finalmente las hay que muestran muy breves apariciones del macedonio en biografías de otros personajes, como su encuentro con el filósofo que da nombre a Diogène, de Yves Duval y Fred y Liliane Funcken, publicado en Tintin tanto en la edición belga ( $. .940,6$ de octubre de 1960) como en la francesa (n. 630, 17 de noviembre de 1960, pp. 4-8), o la evocación de su figura por parte de un Julio César admirado ante su estatua en el templo de Hércules-Melkart de Gades en Un Grand Romain: Jules César, con texto de Octave Joly y dibujo de Pierre Dupuis (Spirou, n. 914, 20 de octubre de 1955, pp. 24-28, sección "Les belles histoires de l'oncle Paul").

Sin embargo, algunas de esas revistas publicarán asimismo obras más extensas, bien por entregas como Le Glaive de bronze, de Sirius, en Spirou (números 916-935, desde noviembre de 1955 a marzo de 1956), bien en un solo volumen como las versiones francesa y flamenca de la parte gráfica del Alejandro el Magno de Lacier y Campañá antes citado (ed. Bruguera, "Colección Historias", n. ${ }^{\circ} 150,1962$ ), publicadas bajo los títulos Alexandre le Grand en Samedi Jeunesse (n.62, diciembre de 1962, 34 pp. con numeración propia) y Alexander de Grote en Ohee! (n. 14, 20 de julio de 1963, ed. Het Volk) respectivamente ${ }^{41}$, un fenómeno que, como en el caso español, anuncia la futura sustitución de las revistas por el álbum. Entre todas ellas destaca precisamente Le Glaive de bronze, de Sirius, que tras su publicación por entregas aparecerá en formato álbum en 1958 como la cuarta aventura de la serie Images de l'histoire du monde (ed. Dupuis, 44 pp. en color; reed. 1981), también conocida como Les Timour, nombre compartido por los miembros de una misma familia ficticia cuyo devenir a lo largo de los siglos junto a personajes históricos famosos es narrado a través de las aventuras de tantas generaciones de la misma como épocas se recogen en la serie.

\footnotetext{
${ }^{41}$ En ninguna de estas publicaciones se indica la autoría de la obra -únicamente figura el copyright de la Agence Real Presse, de Bruselas- y en la de Samedi Jeunesse se utiliza como portada un dibujo inspirado en la viñeta que muestra la ira de Alejandro ante el asedio de Tiro (p. $12=$ p. 91 del volumen y p. 23 de la parte gráfica en la edición española), rasgos comunes a las ediciones que dicha revista hizo de obras publicadas previamente en España por Bruguera (Inventaire du magazine Samedi Jeunesse 19571973, 2016, s.v. "Bruguera": https://www.jchr.be/langage/samedi-jeunesse.htm\#n62).
} 
Este hecho resulta absolutamente novedoso, pues, a diferencia de las obras que hasta el momento hemos repasado, aquí nos encontramos por vez primera ante un cómic que no se centra en el personaje de Alejandro Magno, cuya presencia se explica en la medida en que aparece relacionado con el protagonista ficticio de la obra, en el marco del subgénero que Thiébaut denomina "bandes dessinées réalistes de fiction". Sin embargo, ello no impide que haya sido considerado no sólo de utilidad didáctica -"una serie muy didáctica, impecablemente documentada", "cuya suave apariencia (sólo la apariencia) permite una aproximación sosegada, incluso sabia, en las aulas" (Aziza, 2008, pp. 140 y 127)-, sino modélico dentro de ese ámbito (Visser, 1999; Lochman, 1999). En Le Glaive de bronze el argumento gira en torno al Timour que, junto con su hermano, se une al ejército macedónico en la conquista del Imperio persa, contribuye a salvar la vida de Alejandro en la batalla del Gránico, a alcanzar la victoria en Issos y a frustrar un complot contra el monarca -al modo de la "historia secreta" o ficción verosímil que se desarrolla en un marco histórico, un recurso característico dentro del género de la novela histórica-, pero entre todos estos episodios destaca uno más crítico: aquel en el que Timour se niega a realizar la proskynesis ante el soberano, si bien el desenlace no es tan trágico como en el protagonizado en la historia real por Clito (pp. 31-32). La narración utiliza recursos didácticos desde una primera página destinada a ubicar al lector en el contexto histórico mediante mapas, paneles de texto explicativo y reproducciones de obras artísticas y monumentos, así como a lo largo de la obra tanto mediante esos mismos recursos como con la introducción de viñetas didácticas que con texto e imagen explican el significado social y cultural del symposion (p. 40) o los diferentes tipos de espadas griegas (p. 42), aun cuando estas últimas, al esforzarse por reunir el mayor volumen posible de información en un espacio muy reducido, concentran una información excesiva y en ocasiones secundaria -así las tipologías puramente arqueológicas- que podría haber sido transmitida de un modo más natural -y sutil- sin necesidad de interrumpir de un modo tan drástico la narración (Visser, 1999) ${ }^{42}$.

En adelante todas las obras a las que nos referiremos se presentarán bajo la forma de álbum y cada vez con mayor frecuencia encontramos, junto al modelo biográfico centrado en Alejandro, el ficcional de carácter didáctico que acabamos de identificar

\footnotetext{
42 Paralelamente, el autor recurre también al cine como fuente de información para la representación de los hechos históricos que narra, y así la viñeta que muestra la flota de Alejandro dispuesta para la invasión de Asia (p. 16) toma como modelo una escena de la película Ulisse, dirigida por Mario Camerini en 1954 (Thiébaut, 1999, p. 570).
} 
en Le Glaive de bronze. Todo ello se observa en este momento en dos volúmenes de la serie Alix, de Jacques Martin, publicados por entregas en la revista Tintin y más tarde en un solo volumen por Casterman, que evocan la figura de Alejandro para mostrarlo otorgando a Ptolomeo el gobierno de Egipto en una viñeta de Le Prince du Nil (n. $.11,1974$; trad. esp. El principe del Nilo, Norma, 1982, y Netcom2, 2010) y en la descripción de la batalla de Gaugamela y de sus consecuencias, representado en una estatua, en las bodas de Susa y en el lecho de muerte en La Tour de Babel (n.․ 16, 1981; trad. esp. La torre de Babel, ed. Netcom2, 2011), si bien la limitada extensión de estas menciones no va más allá de la simple reproducción de tales episodios con la riqueza y calidad en la ambientación histórica características de esta colección ${ }^{43}$. Y lo mismo se observa en las dos páginas creadas en 1985 por el mismo autor con motivo de la publicación, por una parte, de un número especial de la revista À suivre dedicado a la arquitectura en el cómic y, por otra, de la organización de una exposición en Angulema sobre el mismo tema que presentan un episodio ficticio asociado a la llegada de Alejandro a la ciudad de Priene (NetComic, 2012), así como en la ilustración "Le tombeau d'Alexandre" incluida en el volumen L'Odyssée d'Alix (Casterman, 1987; reed. L'Odyssée d'Alix (1), 1999).

A partir de octubre de 1978 Larousse publicó en color la colección "La découverte du monde en bandes dessinées", cuyo primer número, bajo el título De l'Atlantique à l'Inde. Ulysse et Alexandre Le Grand, recoge las aventuras del héroe homérico y la biografía del conquistador macedonio. La parte dedicada a Alejandro (pp. 74-96), con dibujos de Carlo Marcello y guión de Pierre Castex con la colaboración de François Debreczeni, disfrutó de gran popularidad y fue objeto en 1981 de varias traducciones $^{44}$, entre ellas al español con el título Tras las huellas de Alejandro, dentro del volumen Ulises. Alejandro Magno editado por Planeta Cómic como n. 02 de la colección "Grandes Héroes. El descubrimiento del mundo". La primera página del volumen muestra una breve introducción común a las dos historietas titulada "Vencer lo desconocido" y una cronología que alcanza desde la Guerra de Troya (1200-1180 a.C.) hasta la muerte de Alejandro en 323 a.C. (p. 4). Aunque en la narración se

\footnotetext{
${ }^{43}$ Thiébaut (1999, p. 615) apunta hacia la influencia que sobre la viñeta de las bodas de Susa habría ejercido la representación de las mismas recogida en el reportaje "In the Footsteps of Alexander the Great" publicado en enero de 1968 en la revista National Geographic (Schreider y Schreider, 1968, pp. 64-65).

${ }^{44}$ Alemán: Alexander der Große, n. ${ }^{\circ} 16$ de la colección "Die Eroberung der Welt". Finlandés: Aleksanteri Suuri, n. ${ }^{\circ} 5$ de la col. "Historian Suuret Seikkailut". Portugués: Alexandre da Macedónia, n. ${ }^{\circ} 1$ de la col. "A descoberta do mundo. Uma história universal em banda desenhada".
} 
impone el recurso a textos explicativos frente a unos diálogos que no hacen sino reforzarlos, sin embargo en conjunto resulta especialmente dinámica gracias a la combinación en todas las páginas de viñetas abiertas y cerradas y un muy acertado uso del color, por ejemplo para diferenciar entre presente y pasado e incluso dentro de éste entre la asociación del pasado helénico con la cerámica de figuras rojas (p. 75) frente a los colores terrosos del egipcio (pp. 82-84) y los tonos amarillos utilizados al evocar la infancia de Alejandro (pp. 76-77). Esta obra ha sido utilizada como material didáctico destinado a la impartición del tema de Alejandro Magno en aulas de Educación Secundaria tanto en su edición original por parte de docentes franceses en el marco de una presentación interactiva en PowerPoint ${ }^{45}$, como en su traducción al español como lectura recomendada por un libro de texto de Bachillerato ${ }^{46}$.

Iniciada la década de 1980 encontramos dentro de la bande dessinée una serie y una obra caracterizadas por una gran calidad e independientes entre sí, pero íntimamente ligadas. La primera consta de dos títulos, Le Triérarque sans nom (ed. Lavauzelle, 1985) y Les clefs de Jérusalem (ed. Soleil, 1992), con guión de Serge Saint-Michel y dibujo de Jean-Marie Ruffieux, que de nuevo no constituyen una biografía más de Alejandro, sino que conforman un relato de aventuras protagonizado por un personaje ficticio: Demetrio, hijo del supuesto autor del incendio del Artemision de Éfeso y oficial de la flota macedónica, el cual, en su afán por vengar las consecuencias de la falsa acusación contra a su padre e injustamente acusado de traición por Alejandro, se enfrenta a éste durante el asedio de Tiro en el primer volumen y posteriormente en Gaza y en Jerusalén en el segundo. A pesar de tratarse de una obra ficcional y, por añadidura, inconclusa -a los dos títulos publicados se debería haber sumado un tercero, Le fils d'Amon, proyecto que no llegó a desarrollarse-, sin embargo ha sido valorada como "la serie más interesante" entre las que incorporan la presencia de Alejandro Magno en la medida en que aúna "la belleza del diseño, el rigor histórico y el aliento de la aventura" (Aziza, 2008, p. 157). Más allá de un mapa acompañado por el único cuadro de texto explicativo presente en el primer volumen, la obra informa

\footnotetext{
${ }^{45}$ Esta presentación de 38 diapositivas ha sido publicada en varios blogs de docentes a partir del curso 2010/2011 y todavía puede ser consultada bajo el título Alexandre le Grand. Lire une bande dessinée pour miex connaître son épopée en https://www.slideserve.com/russell/alexandre-le-grand.

46 Así el volumen Griego. 2o Bachillerato publicado por Editex en 2009, el cual, dentro del apartado "Sugerencias" de la sección "Enthousiasmós" correspondiente a la Unidad didáctica 7, dedicada a Alejandro Magno, presenta este cómic como "un relato tradicional destinado a la glorificación del joven macedonio, ilustrado por los episodios más míticos de la ascensión de Alejandro" (Almodóvar García y Gómez Tirado, 2009, p. 116).
} 
acerca del mundo en el que vivió Alejandro no mediante los consabidos textos explicativos que pautan -y a menudo lastran- el relato, sino a través de la simple representación gráfica de protagonistas -indumentaria, armas, herramientas-, escenarios -monumentos arquitectónicos, decoración doméstica, barcos-y elementos diversos -técnicas de navegación, de asedio, ceremonias e iconografía religiosas, etc.-, en una línea que delata la influencia de modelos como Alix, de Jacques Martin (Thiébaut, 1999, p. 250), acompañada por muy breves notas ubicadas al pie de las viñetas que en ningún momento alteran un ritmo narrativo basado en un diálogo muy fluido y una acción extremadamente dinámica, todo lo cual convierte a esta serie en uno de los cómics con mayor potencial didáctico a la hora de abordar la época de Alejandro.

Muy próximo a estos dos títulos se halla Alexandre le Grand (ed. Dargaud, 1989; reed. Soleil, 1991), obra con guión y dibujo del mismo Ruffieux elaborada paralelamente a la creación de aquéllos, pero desde una perspectiva diferente: el formato ficcional que presentaba a Alejandro como enemigo del protagonista queda aquí desplazado por el biográfico que sitúa a Alejandro en el centro de la narración. Sin embargo, y aun cuando ha sido considerada como "una buena biografía" (Aziza, 2008, p. 156), no encontramos en ella el típico relato que, como en tantos otros casos ya repasados, se extiende desde los prodigios asociados al nacimiento del personaje hasta su muerte en Babilonia, pues comienza con el asesinato de Filipo y se informa a posteriori de éxitos previos de Alejandro como Queronea o las campañas contra los tracios. Ello es consecuencia de la fidelidad del autor hacia la fuente de información en la que se inspira, una de las más importantes sobre el personaje, la Anábasis de Alejandro de Flavio Arriano (siglo II d.C.), cuyo autor actúa además como narrador que abre y cierra la obra y con cuya presencia Ruffieux se propone ilustrar al lector acerca de la fuente literaria de la que proceden las informaciones sobre el personaje para, indirectamente, dotar de fiabilidad histórica a su propio trabajo ${ }^{47}$. A ello contribuye además la incorporación de mapas generales en las guardas y específicos en viñetas a lo largo de la obra (Anatolia, p. 14; Egipto, p. 23; Mesopotamia e Irán, p. 34; la ruta por Asia, p.

\footnotetext{
${ }^{47}$ El mismo recurso del autor-narrador-protagonista es utilizado en el manga Plutarch no Eiyuudensetsu. Heros biographia. Plutarch Lives, de Hiroshi Sato ([Los héroes de Plutarco], ed. Ushio Shuppansha, 2012; reed. Kibo Comics, 2014), con Plutarco en tanto que autor de la biografía de Alejandro adaptada en esta obra, mientras que en Alexandros. Sekai Teikoku e no Yume, de Yasuhiko Yoshikazu (2003, ed. NHK; trad. it. Alessandro Magno. Il sogno dell'impero mondiale, Yamato edizioni, 2006), la función de narradorprotagonista es asumida por Lisímaco, uno de los compañeros de Alejandro, al final de su vida y en tanto que testigo de los acontecimientos narrados (Pelegrín Campo y Delgado-Algarra, en prensa).
} 
39; el cruce del Hidaspes, p. 40), la detallada reproducción gráfica de arquitecturas monumentales (Tiro, Babilonia, Persépolis) y de informaciones sobre la organización de las nuevas conquistas y el nombramiento de los nuevos gobernadores de las satrapías en un relato que no por ello resulta pesado, debido fundamentalmente a una acertada utilización del diálogo que reduce notablemente la presencia de los tradicionales textos explicativos, y aun cuando episodios históricamente significativos carecen de representación gráfica y apenas son mencionados en el texto, como ocurre con el nudo gordiano, la muerte de Darío, la conjura de Filotas y la ejecución de Parmenión o el matrimonio con Roxana.

Con todo, estas obras representan los últimos testimonios que en las décadas finales del siglo XX encontramos de la presencia de Alejandro Magno en la bande dessinée de tema histórico-didáctico centrada en la Antigüedad. Ello debe ser entendido en el marco de una transformación más amplia del género, fenómeno que, según Michel Thiébaut, arranca del nuevo contexto económico y sociocultural generado desde finales de la década de 1960 y que se asocia con el final de la censura y la consiguiente incorporación de la violencia y el erotismo al género, con la desaparición progresiva de la mayor parte de los semanarios destinados al público más joven y con la ausencia de referentes históricos en ese mismo público como resultado de la entrada en vigor de unos sistemas educativos que han relegado a una posición secundaria el estudio de las Humanidades en general y de la Antigüedad en particular (Thiébaut, 1999, pp. 803-805; 2015, p. 148).

\section{Alejandro Magno en otros cómics europeos}

Paralelamente a la presencia de Alejandro en el tebeo español y en la bande dessinée franco-belga, no faltan cómics sobre el personaje publicados en otros países europeos durante el siglo XX.

En relación con el cómic didáctico norteamericano ya indicamos que la única colección de este subgénero que disfrutó de una prolongada trayectoria fue la creada por Albert L. Kanter en 1941 como Classic Comics, la cual, editada por él mismo a partir del año siguiente a través de Gilberton Company, cambió su nombre en 1947 por Classics 
Illustrated ${ }^{48}$. Esta serie alcanzó una enorme popularidad y contó con numerosas reediciones y traducciones publicadas hasta en 26 idiomas en 36 países, en los que incluso dio lugar a la aparición de nuevos volúmenes (Jones, 2011). Así sucedió particularmente en Grecia, donde a partir de 1951 la editorial Atlantis-Pechlivanidis

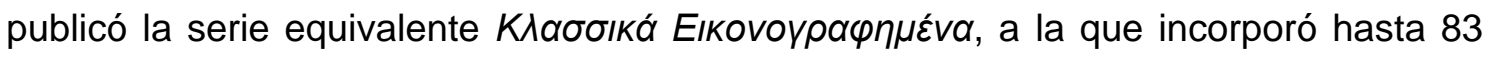
números originales sobre temas de historia y mitología griegas en un contexto, el de los años posteriores a la Segunda Guerra Mundial y a la guerra civil griega, marcado por la construcción esencialista de una determinada definición de la identidad helénica y de la nación griega por parte de un poder político que para ello buscaba una justificación ideológica en el pasado histórico y cultural (Skarpelos, 2000, pp. 19-20 y 151 y ss.; Moula, 2010, pp. 142-143; Nikolaou, 2017, pp. 64-66; vid. en general Kazamias, 2014) $)^{49}$. Como parte de ese pasado al que tan interesadamente se recurre desde el presente -resultan especialmente significativos en este punto tanto el lema

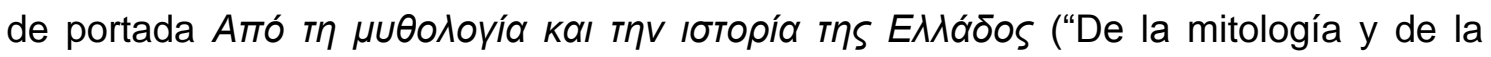
historia de Grecia") como el espíritu que anima la introducción de los editores a cada volumen- y al igual que otros números están dedicados a la tragedia clásica y a grandes personajes de la historia helénica, Alejandro protagoniza en esos primeros

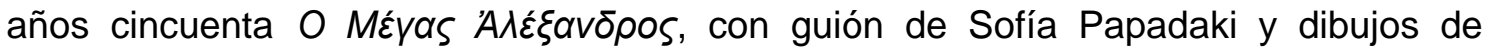
Vassilis Zissis (n. ${ }^{105}$, s.f.). El estilo casi naif de estos últimos contrasta con el tono épico que, desde la introducción, domina en las 48 páginas en color de una narración que repasa la vida del conquistador y en la que los abundantes textos explicativos se imponen a unos diálogos muy limitados en un relato marcado por el protagonismo de Cinane, hermanastra de Alejandro que, a diferencia de la realidad histórica, aquí lo acompaña en su expedición por Asia. Esta misma obra será reeditada con los números 154 y 231 y, en una segunda época de la colección iniciada en 1975,

\footnotetext{
${ }^{48}$ Con Classics Illustrated Kanter se propuso dar a conocer los clásicos de la literatura occidental a través de versiones resumidas e ilustradas, más atractivas para un público infantil y juvenil por otra parte ya acostumbrado a la lectura de cómics. De hecho, al final de cada número un anexo informaba acerca de la obra original y recomendaba al lector acudir a su escuela o a su biblioteca local para disfrutar directamente de ella: "Now that you have read the Classics Illustrated edition, don't miss the added enjoyment of reading the original, obtainable at your school or library" (Kovacs, 2011, p. 21; Moula, 2012, p. 591).

${ }^{49}$ Una utilización similar de la figura de Alejandro Magno en el cómic se observa en aquellos números de la serie india Amar Chitra Katha en los que aparece este personaje (Chanakya, n.․ 21, 1971, ed. India Book House; Megasthenes, n.․ 384, 1987, id.; y, sobre todo, Paurava and Alexander, n.. 179, 1978, id.), si bien allí actúa no como un paradigma para la definición de la helenidad, sino como un recurso destinado a contribuir indirectamente a la construcción de una particular identidad india homogénea, inmutable y atemporal por oposición a una alteridad plasmada en la fórmula casi igualmente atemporal del invasor extranjero por cuanto a lo largo de la historia identifica como tal lo mismo a británicos que a musulmanes o, como en el caso que nos ocupa, griegos y macedonios a las órdenes de Alejandro (Pelegrín Campo y Delgado-Algarra, en prensa).
} 
reaparecerá con el 1011 (de acuerdo con una numeración que comienza con el 1001) tanto con la misma portada como con una nueva, más realista, e incorporando un anexo didáctico de cuatro páginas de las que dos están ocupadas casi por completo por un mapa del imperio de Alejandro y del camino recorrido en sus conquistas ${ }^{50}$.

Paralelamente, una obra completamente diferente fue publicada con diversos títulos, pero siempre sin firma, en otras versiones europeas de Classics Illustrated editadas en 1966 en Suecia (Alexander den Store), Dinamarca (Alexander den Store), Noruega (Aleksanders erobringer), Finlandia (Aleksanteri Suuren Valloitukset) y Holanda (Alexander de Grote), y en 1969 en la República Federal de Alemania (Alexander der Große $)^{51}$. Todas ellas forman parte de lo que se conoce como Classics Illustrated JES (Joint European Series), fórmula acuñada para designar al conjunto de títulos editados y reeditados en Europa en los idiomas mencionados, pero nunca en inglés, y sin incluir la edición griega ni tampoco la ya citada edición en español Las conquistas de Alejandro por haber sido publicada en 1969 en la versión mexicana de la serie original, denominada Clásicos Ilustrados y editada por La Prensa. A lo largo de 32 páginas a todo color los textos explicativos, presentes en todas las viñetas, se imponen a unos diálogos prácticamente inexistentes -rara vez aparece más de un bocadillo por viñeta, y a menudo no figura ninguno- junto a un dibujo muy diferente al naif de la versión griega, pero que, a la vista una vez más del casco y de la coraza que porta Alejandro e incluso del escaso espacio dedicado a la trayectoria del personaje tras Gaugamela -

50 La obra puede ser consultada en

http://www.projethomere.com/travaux/bibliotheque homere/BD grecques/megas alaxandros.htm. Una interesada conexión con determinada imagen de la identidad griega contemporánea remata la obra cuando, tras aludir a la leyenda según la cual en época moderna una sirena continúa preguntando a los

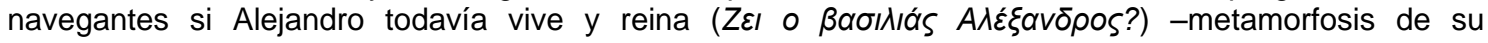
hermanastra Cinane según el cómic, aun cuando la transformación en sirena es atribuida a Neraida, hija de Alejandro, según un pasaje del Pseudo Calístenes (II 41), o a su otra hermanastra Tesalónica según una tradición popular posterior-, en la última viñeta y ocupando toda la página aparece un navío adornado en su mascarón de proa por una sirena y coronado por la bandera griega flanqueado por el siguiente texto: "¡Esta es la verdad! Alejandro no había muerto. De su antorcha recibieron el resplandor los nuevos puestos de avanzada del espíritu y el arte. La difusión de la lengua griega en los países del Este ayudó a difundir el evangelio. A través de los siglos, Alejandro, que es el espíritu y el alma del helenismo, vive y

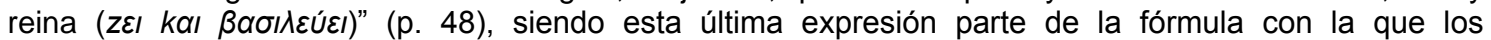

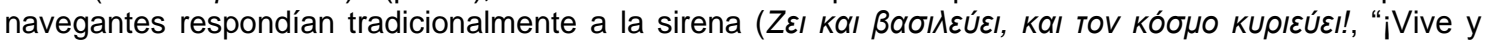
reina y gobierna el mundo!"). A la misma leyenda remite la última viñeta del Alejandro Magno de Montiel y Martín Saurí publicado en 1984 por Bruguera y citado más arriba (p. 30).

51 Alexander den Store (sueco): col. Illustrerade Klassiker, n. 190, ed. Williams Förlags. Alexander den Store (danés): col. Illustrerede Klassikere, n. ${ }^{\circ}$ 190, ed. I.K. (Williams Förlags). Aleksanders erobringer (Las conquistas de Alejandro, en noruego): col. Illustrerte Klassikere, n. 180, ed. Williams Förlags; reed. 2013, $\mathrm{n} .{ }^{\circ} 44$, ed. Hjemmet / Egmont. Aleksanteri Suuren Valloitukset (Las conquistas de Alejandro Magno, en finés): col. Kuvitettuja Klassikkoja, n. 131, ed. Kuvajulkaisut. Alexander de Grote (holandés): col. Illustrated Classics, n. 185, ed. Williams Förlags. Alexander der Große (alemán): col. Illustrierte Klassiker, n. -165 , ed. BSV-Williams; reed. 1991, n.ํ 121, ed. Norbert Hethke Verlag. Vid.: https://www.comics.org/issue/91701/\#1529781. 
de nuevo tan sólo tres páginas-, delata la influencia de la película de Rossen y/o de su versión en cómic editada por Dell. Finalmente tanto los números editados en Grecia como los JES han sido publicados en inglés a partir de 2008 por Classic Comic Store y entre ellos los números referidos a Alejandro editados en cada una de esas colecciones, en el primer caso bajo el título Alexander the Great of Macedonia (Classics Illustrated - G [en referencia a la Greek Series], n. ํ 6) y en el segundo como Alexander the Great (Classics Illustrated - JES, n.․ 12) ${ }^{52}$.

En el ámbito alemán, en la República Federal encontramos en 1955 la obra Alexander der Grosse. Ein Weltreich zu Füssen, de Lothar Linkert (n. 19 de la colección "Abenteuer der Weltgeschichte", ed. Lehning Verlag), cuyas 31 páginas comienzan con la presentación de los principales protagonistas -Alejandro, el general Skopas, el asesino Pausanias y el general Antipratos ( $\mathrm{sic}$ - y una breve introducción para, a continuación, seguir un esquema fijo de seis viñetas en negro y rojo con textos al pie que acogen tanto explicaciones como diálogos. El relato, que arranca con la conspiración de Pausanias contra Filipo y finaliza con la batalla de Gaugamela, está plagado de intrigas y no resulta especialmente respetuoso con los hechos históricos, si bien la última página incorpora un mapa con todas las conquistas de Alejandro y la ruta que siguió en su avance por Asia (p. 31) ${ }^{53}$. Por otra parte, en ese mismo 1955 la República Democrática Alemana veía nacer la revista mensual Mosaik, destinada a transmitir los valores socialistas a un público infantil y juvenil en respuesta a la Micky Maus editada desde 1951 en la República Federal de Alemania (Knigge, 2010, p. 17). Creada y dirigida por el ilustrador Hannes Hegen (pseudónimo de Johannes Hegenbarth), Mosaik se proponía combinar el elemento lúdico y el didáctico a lo largo de 24 páginas bajo la forma de grandes viñetas en color, con un dibujo caricaturizado, sin bocadillos y con textos al pie, a través de las peripecias que en diferentes momentos históricos vive el trío protagonista, los Digedags, sustituidos tras la marcha

\footnotetext{
${ }^{52}$ La versión en inglés de la edición griega no recoge la autoría de Papadakis y Zissis, mientras que la de la edición JES aparece firmada por "Polybius", una fórmula que no sólo oculta al responsable del texto al modo de los números de la edición estadounidense de Classics Illustrated que adaptaban obras clásicas y atribuían el texto moderno a los autores originales -y así The Last Days of Pompeii aparece firmado por Edward Bulwer-Lytton y el dibujante Jack Kirby, mientras que en Julius Caesar figuran el mismo César y el ilustrador Joe Orlando (Kovacs, 2011, p. 21)-, sino que incluso introduce una autoría que ni siquiera se corresponde con la realidad histórica, pues las Historias de Polibio no incluyen ninguna biografía de Alejandro.

${ }^{53}$ La obra puede ser consultada en https://comicbookplus.com/?dlid=26934. En Gaugamela Alejandro aparece combatiendo sobre un carro con cuchillas en las ruedas y conquista la victoria gracias a la deserción de unos beduinos del lado persa y a la fidelidad de Skopas, un general que había perdido injustamente la confianza del rey.
} 
de Hegen en 1975 y todavía en la actualidad por otro trío, los Abrafaxes. En Das Wrack des Nearchos, con texto de Lothar Dräger y dibujo de varios ilustradores ( $\mathrm{n} .^{-}$ 137, abril de 1968, ed. Verlag Junge Welt), los Digedags se encuentran en el siglo XIII y el hallazgo de un barco naufragado en el Golfo Pérsico que perteneció a la flota de Nearco y en el que ellos mismos viajaron les recuerda sus aventuras muchos siglos antes como correos de Alejandro Magno, el cual aparece en Der Kampf um den Wüstenbrunnen (n. 138, mayo de 1968) departiendo con sus generales en su campamento de la India hasta decidir el regreso a Babilonia al recibir noticias preocupantes de sus dominios (transmitidas precisamente por los Digedags, pp. 6-8), despidiendo a Nearco y su flota (p. 11) y emprendiendo el viaje por tierra (pp. 12-13) ${ }^{54}$. Y posteriormente en Der Gerichtstag, igualmente con guión de Dräger ( $n . \stackrel{0}{1 / 84}$, enero de 1984), la figura de Alejandro será evocada de un modo genérico en una doble página que incluye dos párrafos sobre el conquistador, un mapa de sus conquistas y de su ruta por Asia y sendos dibujos que reproducen un busto escultórico del soberano y el mosaico de Issos (pp. 2-3), a modo de introducción de una nueva aventura de los Abrafaxes que se desarrolla en la India del siglo XIII y que en el número siguiente, titulado Der Schild des Königs Poros (n. 2/84, febrero de 1984), muestra a Alejandro en la batalla del Hidaspes (pp. 5-7), recibiendo a Poros (pp. 8-9) y viéndose obligado a decretar la vuelta a Babilonia ante el rechazo de sus tropas a seguir hacia adelante (pp. 10-12) ${ }^{55}$. La perspectiva ideologizada del relato está presente tanto en la aventura protagonizada por los Digedags como en la de los Abrafaxes a través de un tono abiertamente antiburgués y antiimperialista evidenciado en detalles como la representación de los mercaderes, los cuales, ante los peligros del viaje de Nearco y en repetidas ocasiones, se muestran más preocupados por sus bienes que por la supervivencia común en el primer caso (números 138 y 139, mayo y junio de 1968 respectivamente), o el hecho de que sea la voluntad de los soldados reunidos en asamblea -al modo de los soviets- la que impone a Alejandro la decisión de volver al Oeste en el segundo (n. $\stackrel{2}{2} / 84$, febrero de 1984, pp. 10-11).

\footnotetext{
${ }^{54}$ Entre los argumentos históricos citados para justificar el retorno figuran las pérdidas causadas en la campaña de la India, la herida de Alejandro, las lluvias y el cansancio de los soldados y problemas en el Imperio como la traición del tesorero Harpalo; por el contrario, el mapa que preside la reunión incluye la ciudad de Basora, fundada casi mil años más tarde (p. 8).

${ }^{55}$ Kramer (2004, p. 38, notas 101 y ss.) destaca el detallado tratamiento de la Antigüedad en Mosaik y las fuentes utilizadas para ello, que en el caso de Alejandro llegan a incluir el ya mencionado reportaje "In the Footsteps of Alexander the Great" publicado en National Geographic (vid. supra, n. 43).
} 
Si en relación con el cómic británico ya apuntamos la aparición en 1956 de versiones en cómic de la película de Rossen -tanto la publicada antes por Dell, editada en este caso por World Distributors, como una versión resumida recogida en la revista Express Weekly-, a finales de 1963 la antología anual Valiant correspondiente a 1964 incluye Conqueror of the World (pp. 89-97, ed. IPC Magazines), que, con texto de Michael Moorcock y dibujo en color de Ron Embleton, repasa los episodios más conocidos de la biografía de Alejandro en una sucesión de ilustraciones acompañadas por párrafos explicativos y escasísimos diálogos. Y entre junio y agosto de 1964 aparecerá sin firma Alexander the Young a lo largo de nueve entregas semanales en la revista Hotspur (números 245-253, ed. D. C. Thompson \& Co.): con un total de 25 páginas en blanco y negro, diálogos muy ágiles y textos explicativos reducidos a su mínima expresión, esta obra destaca la valentía y sagacidad del protagonista a través de sus hazañas de juventud, desde la doma de su caballo y la victoria de Queronea hasta, ya proclamado rey de Macedonia, las campañas contra tracios, tribalios, escitas y peonios, si bien las defensas de las ciudades resultan más propias de un castillo medieval y, lo más importante, gráficamente todavía se inspira de un modo muy marcado en la edición de Dell, y no sólo por la apariencia del yelmo y de la coraza de Alejandro, sino incluso por la representación misma del personaje ${ }^{56}$.

Finalmente, el escaso interés que Alejandro ha despertado en el fumetto italiano de carácter histórico-didáctico bien puede deberse a su ausencia de protagonismo en la historia de la Roma antigua. Por una parte, de una temprana obra en cuatro páginas con dibujo de Segna Pini publicada por Edizioni Alpe tenemos noticia a través de su traducción francesa Alexandre le Grand (Plutos présente Tex, n.ำ12, marzo de 1953) (Thomasian, 2018b). Pero posteriormente sólo encontramos Alessandro, con guión de Renata Gelardini y dibujo primero de Gino d'Antonio y más tarde de Giorgio Trevisan, publicado por entregas semanales entre enero y mayo de 1965 en el semanario II Vittorioso (números 1-19, enero-mayo de 1965, ed. Società Editrice A.V.E.) ${ }^{57}$. En conjunto todas ellas suman 48 páginas a lo largo de las cuales se desarrolla una detallada biografía del personaje apoyada en elementos didácticos como los siete mapas que la acompañan, pero también más dinámica que la mayoría gracias a la

\footnotetext{
${ }^{56}$ Basta comparar algunas de las representaciones de Alejandro en las páginas pp. 20 y 27 del n. 219 con las que figuran en las páginas 12 y 15 de la edición de Dell.

${ }^{57}$ Editado por Azione Cattolica con una marcada finalidad didáctica, // Vittorioso había nacido en enero de 1937 como alternativa tanto al cómic fascista como al cómic de inspiración norteamericana y continuó publicándose hasta diciembre de 1966 (Fava, 2014).
} 
incorporación de elementos propios del relato de aventuras, como la incursión de Alejandro en el campamento persa la víspera de la batalla del Gránico (pp. 13-14) el encuentro con Roxana al pie de la Roca Sogdiana (pp. 34-36) o la caza del tigre junto a Poros (pp. 43-44) $)^{58}$.

\section{Conclusión}

La publicación del primer cómic protagonizado por Alejandro Magno a mediados de la década de 1920 en las tiras de prensa norteamericanas inaugura una aproximación histórico-biográfica dotada de una clara finalidad didáctica que se revelará característica de la mayor parte de los títulos publicados a lo largo de casi un siglo desde entonces y que continúa vigente en la actualidad. En esa línea, los años 40 contemplan en Estados Unidos el nacimiento y el desarrollo de un cómic específicamente educativo, si bien en un contexto histórico marcado por la Segunda Guerra Mundial que determinará la identificación del conquistador macedonio como paradigma del héroe militar, valiente y victorioso en el combate y su asociación ideológica con valores defendidos por este país como la defensa de la libertad y la lucha contra la tiranía. Una vez finalizada la contienda, esa perspectiva se desdoblará para mostrar a Alejandro por un lado en un cómic de finalidad puramente educativa, pero de extensión cada vez más limitada hasta reducir su presencia a lo meramente anecdótico, y, por otro, en un cómic propagandístico que retoma periódicamente la imagen nacida durante la Segunda Guerra Mundial en revistas de tema bélico coincidiendo con el desarrollo de otros conflictos que contaron igualmente con la participación militar de los Estados Unidos, como los de Corea y Vietnam.

Paralelamente, la presencia de Alejandro en el cómic europeo se caracteriza por una perspectiva histórico-biográfica destinada a un público infantil y juvenil y, en consecuencia, a menudo cargada de intención moralizante desde la publicación del primer título en la España de 1942 y con un especial desarrollo en el ámbito de la bande dessinée franco-belga a partir de la década siguiente. Con todo, no faltan ejemplos de este tipo en otros países europeos, algunos de los cuales resultan de

\footnotetext{
${ }^{58}$ En 1974 todas las entregas fueron reunidas en un único volumen editado en flamenco y sin indicar la autoría bajo el título Alexander de Grote en la colección "Historische strips" (ed. Nederlandse Rotogravure mij N. V.).
} 
particular interés en tanto que producto de un determinado contexto histórico, como los publicados en la Grecia de los años posteriores a la Segunda Guerra Mundial y a la guerra civil o en la República Democrática Alemana.

Tanto en los Estados Unidos como en Europa, las dos últimas décadas del siglo XX contemplan la generalización del interés por un nuevo tipo de cómic, muy diferente respecto de aquel de tema histórico-biográfico cuya misma existencia el primero llegará a amenazar. Más allá de la excepción representada durante ese período por la revista francesa Vécu, en el marco general del cómic de tema histórico y concretamente en el caso de las obras gráficas protagonizadas por Alejandro Magno la práctica desaparición de los títulos de carácter histórico-biográfico publicados coincide con el aumento de los de carácter ficcional que muestran una imagen desmitificada y paródica del personaje desde perspectivas tan diversas como la fantasía, la sátira, la pornografía o los productos destinados a un público infantil. De hecho, dentro de este ámbito Alejandro acabará refugiándose junto a muchos otros personajes históricos en las limitadas parcelas que les otorgarán obras generalistas de historia universal con finalidad claramente didáctica ${ }^{59}$ e incluso bajo la forma de productos derivados de creaciones audiovisuales como resultado de estrategias transmedia ${ }^{60}$. Sin embargo, tal como apuntamos en un trabajo anterior, los años transcurridos desde comienzos del presente siglo han contemplado una revitalización y multiplicación de las aproximaciones didácticas a la historia de Alejandro Magno en el cómic en el marco de un fenómeno de sincretismo cada vez más frecuente entre esa perspectiva histórico-biográfica y la opuesta de carácter ficcional: un fenómeno que se ha generalizado en nuestro mundo globalizado a través de vías muy diferentes y formatos diversificados y en función del cual obras correspondientes al primer grupo

\footnotetext{
59 Por ejemplo los volúmenes Grecia 2, de la colección Historia del hombre (1979, vol. 6, ed. Palsa, México = Grecia IV. Alejandro Magno, col. La gran aventura de la Historia, n. 12, ed. Enciclopedia para todos, Madrid), y Alexandre le Grand, de la colección Les grandes biographies en bandes dessinées (1984, n. 14, ed. Edito-Service), ambos con guión de Alberto Cabado y dibujo de Eugenio Zoppi; la Storia dell'Oriente e dei Greci a fumetti. Dall'Egitto dei faraoni ad Alessandro Magno y La Storia dei popoli a fumetti, ambas dirigidas por Enzo Biagi (1982 y 1997 respectivamente, ed. Mondadori); la ya mencionada The Cartoon History of the Universe: From the Big Bang to Alexander the Great, de Larry Gonick (1990, ed. Broadway Books); la Historia Universal Ilustrada (1992, ed. Roasa); L'extraordinaire aventure d'Alcibiade Didascaux. La Grèce, langue et civilisation d'alpha à oméga, de Clanet y Clapat (1994, ed. Athéna); y la entrega Alexander the Great del coleccionable Wally's History of the World (1997-1998, n. ㅇ, ed. Cooper Clegg), como ya apuntamos en Pelegrín Campo (2019).

${ }^{60}$ Así en las dos partes que conforman Les Premiers Empires. Le Siècle de Périclès, volumen n. ${ }^{3}$ de la colección Il était une fois... l'homme (1978, Éditions Ytra / Éditions Prodifu) que recoge la versión en cómic de los episodios 5 y 6 de la serie televisiva homónima creada el mismo año 1978 por Albert Barillé (trad. esp. Érase una vez... el hombre, Ediciones Junior S.A., 1979).
} 
recurren a fórmulas propias de la ficción para presentar el producto con mayor atractivo para sus posibles destinatarios, mientras que títulos del segundo grupo incorporan a sus tramas elementos históricos e incluso de carácter didáctico propios de las primeras destinados a facilitar y aumentar la comprensión de la historia del personaje y su época entre un público lector tanto adulto como en edad escolar (Pelegrín Campo, 2019: 383-387). Así, en fechas recientes la aproximación postmoderna al personaje nos ha proporcionado representaciones del mismo tan diferentes entre sí como la caricaturizada del Alejandro torpe y divertido de Bart Proost en Alexander De Grote (2011-2021, eds. primero Brabant Strip y posteriormente Strips2Go!) y la realista del taimado manipulador que protagoniza el volumen correspondiente de la colección Ils ont fait l'histoire (Alexandre le Grand, 2018, con guión de David Goy y Luca Blengino y dibujo de Antonio Palma, ed. Glénat / Fayard), herederos ambos en última instancia de la misma tradicional perspectiva históricobiográfica en la que se enmarca su imagen a la vez como general victorioso, paradigma del conquistador, héroe civilizador y aventurero protagonista de un amplio anecdotario transmitida desde el primer momento por las tiras de prensa y las revistas infantiles norteamericanas, pero también tiránico e irracional, y lo mismo reducido a simple herramienta de márketing cinematográfico que elevado a modelo de comportamiento en contextos muy diferentes. Con ello constatamos el retorno de un tratamiento histórico-biográfico del personaje que ha caracterizado la mayor parte de sus representaciones en el cómic durante casi un siglo y a propósito del cual una vez más debemos concluir, al igual que en trabajos anteriores (Pelegrín Campo, 2008: 18; 2019: 388), evocando la conocida reflexión de Paul Cartledge

¿qué clase de hombre era, en la medida en que era un hombre (y no un dios o un héroe)? ¿Era el Alejandro sensato de Ulrich Wilcken?, ¿el Alejandro caballeresco y visionario de W. W. Tarn?, ¿el Alejandro titánico y semejante a un Führer de Fritz Schachermeyr?, ¿el Alejandro heroico al modo homérico de Robin Lane Fox? ¿o el Alejandro amoral y despiadadamente pragmático de Ernst Badian y Brian Bosworth? (...) ¿O no era ninguno de estos, o tenía algo de todos o de algunos de ellos? Faites vos jeux, mesdames et messieurs (Cartledge, 2004, p. 219).

\section{Agradecimientos}

Trabajo realizado en el marco de la actividad desarrollada por el Grupo de investigación ARGOS, financiado por el Gobierno de Aragón (S50_20R) y cofinanciado con FEDER 2014-2020 "Construyendo Europa desde Aragón”. 


\section{Referencias}

Almodóvar García, J. y Gómez Tirado, J. M. (2009). Griego. 2º Bachillerato. Editex.

Antela-Bernárdez, B. y Prieto Arciniega, A. (2008). Alejandro Magno en el cine. En M. a J. Castillo Pascual (Ed.), Congreso Internacional Imagines, La Antigüedad en las Artes Escénicas y Visuales (pp. 263-279). Universidad de La Rioja. https://dialnet.unirioja.es/descarga/articulo/2663361.pdf

Aziza, C. (2008). Guide de l'Antiquité imaginaire. Roman, cinéma, bande dessinée. Les Belles Lettres.

Beaty, B. (2005). Fredric Wertham and the Critique of Mass Culture. University Press of Mississippi.

Ben Sahar, M. (2018). Jews, Samaritans and Alexander: Facts and Fictions in Jewish Stories on the Meeting of Alexander and the High Priest. En K. R. Moore (Ed.), Brill's Companion to the Reception of Alexander the Great (pp. 403-426). Brill.

Blanshard, A. (2018). Alexander as Glorious Failure: The Case of Robert Rossen's Alexander the Great (1956). En K. R. Moore (Ed.), Brill's Companion to the Reception of Alexander the Great (pp. 675-693). Brill.

Brooks, W. (1956). "Alexander" is "the Great"-In Terms of Box Office. Motion Picture Herald (14 de abril de 43-50. https://archive.org/details/motionpictureher203quig/page/n135

Cartledge, P. (2004). Alexander the Great. The Hunt for a New Past. The Overlook Press.

Coletta, Ch. (2010). Famous Funnies. En K. Booker (Ed.), Encyclopedia of Comic Books and Graphic Novels. Greenwood, s.v.

Delisle, Ph. (2010). Spirou, Tintin et $C^{i e}$, une littérature catholique? Années 1930 / Années 1980. Karthala.

Díez, H. (2009). Entre dos aguas (4): Jesús Blasco y Alejandro Magno. Cómic, historietas, tebeos... http://comic-historietas.blogspot.com.es/2009/09/entre-dos-aguas-4-jesusblasco-y.html

Duncan, R., Taylor, M. R. y Stoddard, D. (2016). Creating Comics as Journalism, Memoir and Nonfiction. Routledge.

Fava, S. (2014). «ll Vittorioso»: a magazine for youth education beyond Italian fascist propaganda. History of Education \& Children's Literature, 9(1), 649-666.

Fernández Sarasola, I. (2011). ¿Héroes o villanos? Comics y derechos fundamentales en Estados Unidos. Belphégor. Littérature populaire et culture médiatique, 10(2). https://www.unioviedo.es/constitucional/miemb/ignacio/Estudiocode4.pdf

Fernández Sarasola, I. (2013). El régimen jurídico de la historieta en la España franquista (1938-1949). Historietas, 3, 21-41. https://rodin.uca.es/xmlui/handle/10498/16407

Hajdu, D. (2018). La plaga de los cómics. Es Pop Ediciones (orig. 2008).

Jacobs, D. (2013). Graphic Encounters. Comics and the Sponsorship of Multimodal Literacy. Bloomsbury. 
Jenkins, Th. E. (2011). Heavy Metal Homer: Countercultural Appropriations of the Odyssey in Graphic Novels. En G. Kovacs y C. W. Marshall (Eds.), Classics and Comics (pp. 221235). Oxford University Press.

Jones, W. B., Jr. (2011²). Classics Illustrated. A Cultural History. McFarland (orig. 2002).

Kazamias, A. (2014). Antiquity as Cold War Propaganda. The Political Uses of the Classical Past in Post-Civil War Greece. En D. Tziovas (Ed.), Re-imagining the Past. Antiquity and Modern Greek Culture (pp. 128-144). Oxford University Press.

Knigge, A. C. (2010). Made in Germany. Notes sur l'histoire de la bande dessinée en Allemagne. Germanica, 47, 11-24. doi: https://doi.org/10.4000/germanica.1082

Kovacs, G. (2011). Comics and Classics: Establishing a Critical Frame. En G. Kovacs y C. W. Marshall (Eds.), Classics and Comics (pp. 3-24). Oxford University Press.

Kramer, Th. (2004). Heron und Alexander der Große im Comic. Antikerezeption in der DDR zwischen ideologischem Kalkül und Authentizitätsanspruch. Das Altertum, 49(1), 21-49.

Lepore, J. (2014). The Secret History of Wonder Woman. Alfred A. Knopf.

Lochman, T. (1999). Neue Geschichten zur Alten Geschichte. En Id. (Ed.), "Antico-mix". Antike in Comics (pp. 92-105). Skulpturhalle Basel.

Lopes, P. (2009). Demanding Respect. The Evolution of the American Comic Book. Temple University Press.

Macarro, J. (2015). Alejandro Magno según Robert Rossen. En F. Salvador Ventura (Ed.), Cine e Historia(s). Maneras de relatar el pasado con imágenes (pp. 407-421). Université Paris-Sud.

McCay, W. (2005). Early Works, V. Checker Book Publishing Group.

Méon, J.-M. (2009). L'illégitimité de la bande dessinée et son institutionnalisation: le rôle de la loi du 16 juillet 1949. Hermès. La Revue, 54, 45-50. doi: https://doi.org/10.4267/2042/31554

Mickwitz, N. (2014). Comic and/as Documentary: the implications of graphic truth-telling. Tesis doctoral defendida en la University of East Anglia en marzo de 2014. https://ueaeprints.uea.ac.uk/48686/1/N. Mickwitz PhD E\%2D thesis.pdf

Moreno Leoni, Á. (2017). Alejandro Magno como "conquistador-civilizador": la lectura ilustrada de Flavio Arriano y Plutarco entre los siglos XVIII-XIX. En J. Espino Martín y G. Cavalletti (Eds.), Recepción y Modernidad en el siglo XVIII. La Antigüedad Clásica en la configuración del pensamiento ilustrado (pp. 21-57). Instituto de Investigaciones Filológicas - Universidad Nacional Autónoma de México.

Morris-Suzuki, T. (2005). The Past Within Us: Media, Memory, History. Verso.

Moula, E. (2010). How the Historical Context is absorbed into the "Language" of Comic Book for Children: The Case of Greek Tragedies' Adaptation. En A. Shafaei (Ed.), Frontiers of Language and Teaching. Proceedings of the 2010 International Online Language Conference (IOLC 2010) (pp. 140-149). Universal-Publishers.

Moula, E. (2012). Greek Classics through Comic Books: Negotiating cultural tradition under the fidelity pseudo-dilemma. Journal of Literature and Art Studies, 2(6), 587-605. 
NetComic (2012). Alejandro Magno visto por Jacques Martin. NetComic, 14, 8-10.

Nikolaou, K. (2017). Byzantium and its perception in the mid-twentieth century "Classics Illustrated" comic books. Balkan Studies, 52, 61-84. https://www.imxa.gr/files/bsfiles/52/Nikolaou.pdf

Nygard, T. y Tomasso, V. (2016). Andy Warhol's Alexander the Great: an ancient portrait for Alexander lolas in a Postmodern Frame. Classical Receptions Journal, 8(2), 253-275. doi: https://doi.org/10.1093/cri/clv005

O'Connor, P. (2015). The Haunted Tank. En C. J. Miller y A. Bowdoin Van Riper (Eds.), Horrors of War. The Undead on the Battlefield (pp. 107-117). Rowman \& Littlefield.

Ory, P. (1984). Mickey go home! La désaméricanisation de la bande dessinée (1945-1950). Vingtième Siècle. Revue d'Histoire, 4, 77-88. doi: https://doi.org/10.2307/3769488

Pelegrín Campo, J. (2008). Una aproximación didáctica a la historia de Alejandro Magno a través de la literatura infantil y juvenil actual. CLIO. History and History teaching, 34: http://clio.rediris.es/n34/alejandroclio34.pdf

Pelegrín Campo, J. (2011). Nuevas aproximaciones didácticas a la historia de Alejandro Magno destinadas al público infantil y juvenil. CLIO. History and History teaching, 37: http://clio.rediris.es/n37/articulos/pelegrin2011.pdf

Pelegrín Campo, J. (2016). Antigüedad clásica, didáctica de la Historia y manga japonés en el siglo XXI. En L. Arias et al. (Eds.), Estrategias y recursos para la integración del patrimonio y los museos en la educación formal (pp. 249-262). Universidad de Murcia: http://libros.um.es/editum/catalog/view/1721/2401/2171-2

Pelegrín Campo, J. (2019). Alejandro Magno en el cómic: apuntes sobre recepción clásica y didáctica de la Historia. CLIO. History and History teaching, 45, 357-406: http://clio.rediris.es/n45/articulos/357 406 Libre08 Pelegrin.pdf

Pelegrín Campo, J. (en prensa). Alejandro Magno en el tebeo español: entre la biografía didáctica y el cómic de aventuras. En II Congreso Internacional de Estudios Interdisciplinares sobre Cómic. Dibujando historias, más allá de la imagen (Zaragoza, 15-17 de mayo de 2019).

Pelegrín Campo, J. y Delgado-Algarra, E. (en prensa). Alejandro Magno en el cómic de la India y en el manga japonés: identidades, alteridades y didáctica de la Historia. CLIO. History and History teaching, 47.

People Staff (1981). Picks and Pans Review: The Search for Alexander. People, 15(1) (12 de enero de 1981). https://people.com/archive/picks-and-pans-review-the-search-foralexander-vol-15-no-1/

Pérez de Urbel, J. (1941). Las revistas infantiles y su poder educador. Revista nacional de educación, $\quad 1, \quad 55-58 . \quad$ http://www.educacionyfp.gob.es/dctm/revista-deeducacion/1941/194101/1941re01revistas.pdf?documentld=0901e72b81ee5522

Pierre, M. (1979). Les histoires de l'Oncle Paul. En J. C. Faur (Ed.), Histoire et bande dessinée. Actes du deuxième Colloque International Éducation et bande dessinée (La Roque d'Antheron, 17 et 18 Février 1979) (pp. 51-58). Bédésup.

Porcel, P. (2010). Tragados por el abismo. La Historieta de Aventuras en España. Edicions de Ponent. 
Porcel, P. (2011). La historieta española de 1951 a 1970. Arbor. Ciencia, Pensamiento y Cultura, 187(2), 129-158. doi: https://doi.org/10.3989/arbor.2011.2extran2115

Prieto, A. (2011). Alejandro Magno: el cine. En A. Duplá (Coord.). El cine "de romanos" en el siglo XXI (pp. 31-58). Universidad del País Vasco.

Schreider, H. y Schreider, F. (1968). In the Footsteps of Alexander the Great. National Geographic, 133(1), 1-65.

Scott, C. A. (2011). Comics and Conflict: War and Patriotically Themed Comics in American Cultural History From World War II Through the Iraq War. Tesis Doctoral defendida en la Loyola University Chicago. Loyola University. https://ecommons.luc.edu/luc diss/74/

Serradilla, E. (18 de junio de 2013). La guerra de la E.C. Textos para una exposición. En Id., Cómic y algo más (Blog). http://comic.canariasahora.es/2013/06/

Shahabudin, K. (2010). The Appearance of History: Robert Rossen's Alexander the Great. En P. Cartledge y F. R. Greenland (Eds.), Responses to Oliver Stone's Alexander. Film, History, and Cultural Studies (pp. 92-116). The University of Wisconsin Press.

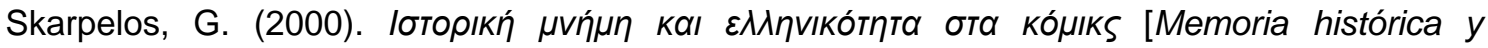
helenidad en los cómics]. Kritiki.

Thiébaut, M. (1999). L'antiquité vue dans la bande dessinée d'expression française (19451995). Contribution à une pédagogie de l'histoire ancienne. Tesis doctoral en microfichas. Atelier National de Reproduction des Thèses.

Thiébaut, M. (2015). D'Alix à Murena: de l'audience de ces deux séries chez les enseignants. En J. Gallego (Dir.), La bande dessinée historique. Premier cycle: l'Antiquité (pp. 145152). Presses de l'Université de Pau et des Pays de l'Adour.

Thomassian, G. (2018a). Supplément à Plutos. En Id., Encyclopédie des bandes dessinées de petit format. http://www.encyclo-bd.fr/encyclocs/lug1/supplutos.pdf

Thomassian, G. (2018b). Tex. En Id., Encyclopédie des bandes dessinées de petit format. http://www.encyclo-bd.fr/encyclocs/lug1/Tex.pdf\#page=1\&zoom=75\#page=1\&zoom=75

Verreth, H. (2005). De oudheid in strips: didactische mogelijkheden en problemen. Prora, 10(2), 3-10. https://bib.kuleuven.be/artes/films-in-de-oudheid/strip-2.pdf

Visser, T. (1999). Von der Kunst, einen guten didaktischen Antiken-Comic zu schreiben. En T. Lochman (Ed.), "Antico-mix". Antike in Comics (pp. 154-169). Skulpturhalle Basel.

Wieber, A. (2008). Celluloid Alexander(s): A Hero from the Past as Role Model for the Present?. En I. Berti y M. García Morcillo (Eds.), Hellas on the Screen. Cinematic Receptions of Ancient History, Literature and Myth (pp. 147-162). Franz Steiner Verlag.

Witek, J. (1989). Comic Books as History. The narrative art of Jack Jackson, Art Spiegelman and Harvey Pekar. University Press of Mississippi. 